\title{
Spatial Openness and Student Activities in an Atrium: A Parametric Evaluation of a Social Informal Learning Environment
}

\author{
Xianfeng $\mathrm{Wu}^{1, *}$, Philip Oldfield ${ }^{2}$ and Tim Heath ${ }^{3}$ \\ 1 China Architecture Design \& Research Group, No.19 Chegongzhuang Street, Beijing, China, 100044. \\ 2 Faculty of Built Environment, University of New South Wales, 2052, Sydney, Australia; \\ 3 Department of Architecture and Built Environment, The University of Nottingham, NG7 2RD, Nottingham, \\ UK. \\ *Corresponding author. China Architecture Design \& Research Group, No.19 Chegongzhuang Street, Beijing, \\ China, 100044; Tel.: +86 18613838910
}

E-mail addresses:

x.wu86@outlook.com (X.Wu); p.oldfield@unsw.edu.au (P. Oldfield); tim.heath@nottingham.ac.uk (T. Heath)

\begin{abstract}
The use of atria for students' informal learning activities is becoming a common architectural design strategy in contemporary higher education buildings, especially in dense urban settings. However, while researchers have focused on the relationship between students' perception, preferences and behaviours in social learning spaces, the spatial attributes themselves tend to be neglected in the literature.

By exploiting digital spatial analysis tools, this paper uses the parameters of 'viewing volume' and 'viewing area' to compare the spatial openness of different spaces within an atrium in a higher education institution. Timeframe capture and interviews are also employed to record the distribution of student activities. The spatial attributes of the atrium and the distribution of student activities are analysed to explore links between the two. The results indicate that the viewing volume in the two-storey-height space is the highest, while viewing area in the staircase space is the highest. These spaces tended to coincide with higher frequencies of 'see and be seen' activities, such as students waiting and looking around $(71.54 \%$ and $56.32 \%$ respectively). The standard deviations of the mean viewing volume and viewing area are the greatest in the three-storey space, suggesting a diversity of spatial openness. This coincided with the highest frequency of activities that require social interactions, such as gathering and group study ( $92.40 \%$ and $58.10 \%$ respectively). These findings suggest that spatial openness can impact student activities in an educational setting, and an atrium specifically. These novel methods also open new horizons for interpreting spatial structure in architecture.
\end{abstract}

Keywords: Spatial Openness; Student Activities; Social Learning; Visibility Analysis; 3D Isovist; Atrium Space 


\section{INTRODUCTION}

Historically, the use of atria evolved with the development of cast-iron structures and the rise of tall buildings in the late $19^{\text {th }}$ century [1]. The inclusion of atria was often to overcome the lack of natural light within deep-plan and complex buildings. Some of the earliest examples are the 'quarter block buildings' of Chicago, which used inner light courts to provide access to daylight and ventilation in early skyscraper designs. The Rand McNally Building (1890), Railway Exchange Building (1904), and People's Gas Company Building (1911) are typical examples [2]. Atria are also integrated into contemporary vertical building designs in dense urban settings due to the potential environmental benefits they offer [3]. Consequently, a significant body of research has focused on their environmental impacts, including daylighting, ventilation, thermal properties, fire performance, etc. [4-10]. Beyond this, the atrium has proven important in establishing a positive image, increasing a user's sense of spaciousness, and enhancing occupant experiences and comfort within a building [11,12]. Atria can also help to create social value and visual communication between floors through their role in shaping socio-cultural meaning and creating a sense of place in different contexts [13-16]. In summary, atrium spaces can provide not only environmental benefits, but can also promote visual perception and vertical movement between floors, facilitating physical activity and social interactions.

The contemporary design of education institutions is increasingly including social spaces to improve the quality and experience of the learning environment, and to enhance informal learning. Such spaces are attractive to students who often spend relatively small amounts of time in formal learning spaces such as lecture theatres, and greater amounts of time in more social and informal environments. Meanwhile, learning is increasingly being seen as a social process, often characterised by students actively seeking discussions with their peers, ultimately contributing to a deeper learning experience $[17,18]$. Such social interaction requires supportive spatial environments that can foster such experiences. Consequently, different models are evolving in the design of multi-storey educational buildings, include student hubs, streets, terraces and more. The use of atria in educational institutions is becoming popular for similar reasons. Education buildings have a need for assembly spaces and significant circulation between formal and informal teaching environments. However, they are increasingly combining such spaces with eating facilities (such as cafes) and relaxing spaces (such as lounges) in an atrium environment, to provide for hybrid activities including social learning [18-20]. The atrium represents perhaps the most dramatic spatial evolution of educational settings developed to support the growing importance of informal learning and social activities [17,21]. With increased densities in cities and higher costs of urban land fuelling more vertical educational facilities, from junior schools to universities, there are now many notable examples of atria in educational settings internationally. These include The New School University Centre in New York, the Diamond in Sheffield, Innovation Tower of Polytechnic University in Hong Kong, and Orestad College in Copenhagen (see Figure 1). 


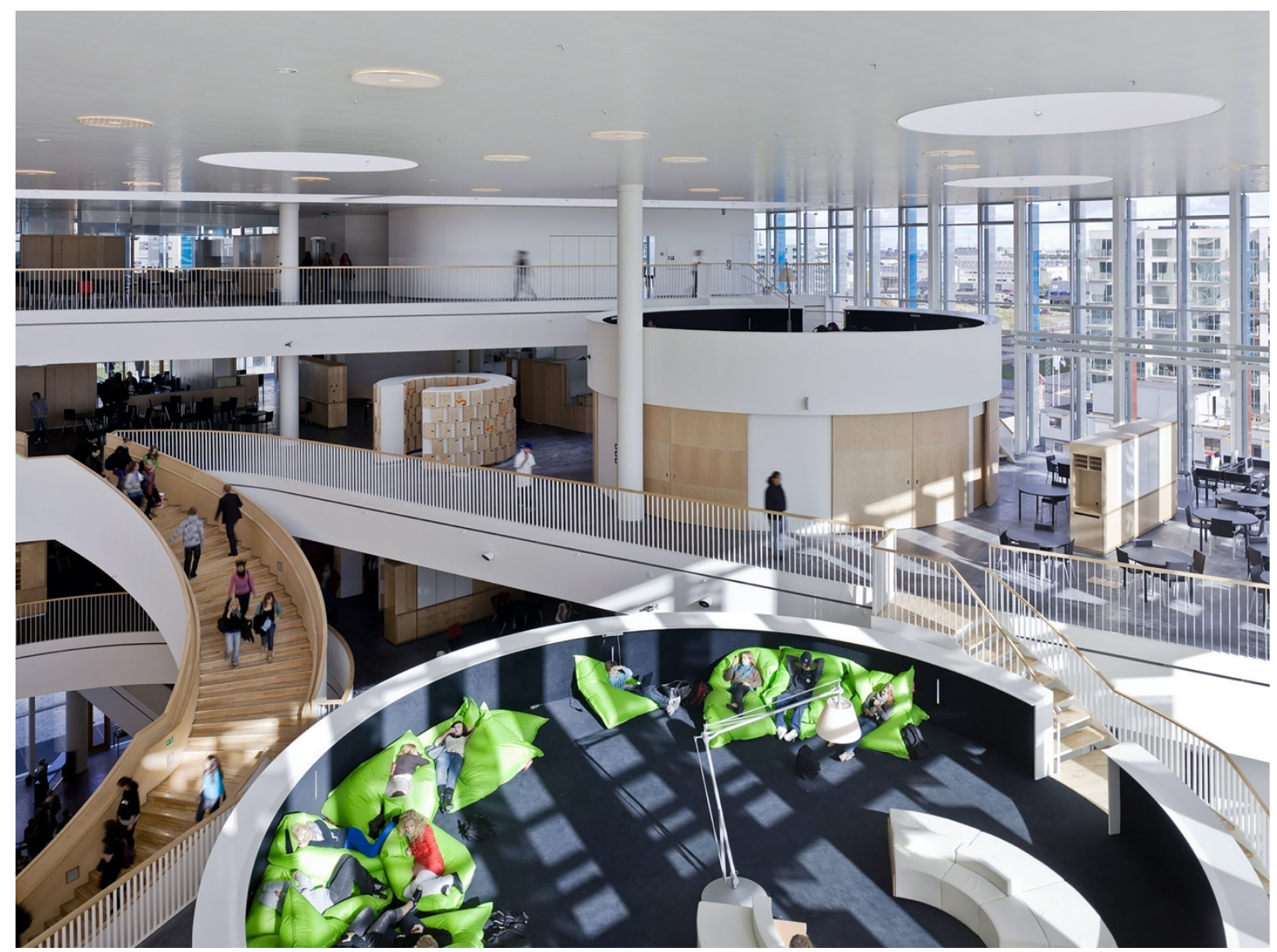

Figure 1. The atrium of Orestad College [22].

Given the increase of social and informal learning spaces, research is emerging to explore the influence that their spatial attributes have on student activities and behaviours. For instance, research has examined the relationship between user behaviour, visual comfort perception, and energy use in formal and informal learning spaces in Portuguese schools, including atria spaces, corridors, stairs and classrooms [23]. Others have shown how visiting informal learning spaces in a museum mitigated the isolating effect of digital learning on students [24]. Crook and Mitchell used audio diaries, direct observation, reflective focus groups and spot conversations to understand how students use social and informal learning spaces in a university library in the UK [25]. Their research examined how the nature of student work, activities in the space, noise, technologies and other factors influenced student behaviour. The findings suggested that students valued the space's 'social ambience' and the importance of being participants in a studying community. But the space was a basement area, and not comparable with multi-storey social learning spaces emerging in dense urban areas, as outlined previously. Some research has used space syntax tools to examine these issues. For instance, VGA analysis, convex analysis and axial analysis has been used along with snapshots and gate counts to show circulation spaces are essential to informal learning in architecture schools as they promote frequent casual interactions [26]. However, in general, research in this field is limited, particularly considering the emerging trend of atrium spaces. For instance, Sailer noted that:

"knowledge on the relationship between spatial configuration and social processes in school buildings, such as teaching, learning, gaining knowledge, interacting, playing and socialising is rather limited as a whole, relying on a small handful of isolated studies." [27] 


\subsection{Visibility analysis of the built environment}

Contemporary computer technology has enabled the development of tools for the simulation and analysis of complex architectural spatial forms. The concept of visualscapes is defined by Llobera [28] as a "spatial representation of any visual property generated by, or associated with, a spatial configuration". To some extent, visualscapes are similar to the concept of 'spatial openness'. Spatial openness can be defined as the volume of free space measured from all possible observation points, and is seen as an important quality indicator of spatial configurations in the built environment [29]. Spatial openness represents a user's feeling of space, and can have an influence their perceived density [29,30]. Visualscapes then focus on the spatial attributes while spatial openness reflects an individual's perception of the space. Visualscapes encompasses analytical techniques such as intervisibility, viewsheds, isovists and visibility graphs. In built environments, visibility analysis is a practical metric which draws upon the knowledge of computing science $[29,31,32]$ and space syntax theory $[33,34]$.

Increasingly, the application of Geographic Information Systems (GIS) is considered an effective way of evaluating visibility in a large-scale area. GIS has been utilised within buildings by many researchers using various tools [31,33-37]. Its application is, however, limited due to its inability to refigure more accurate and complicated interior spaces. In order to overcome these limitations of a raster-based lattice structure model, existing commercial software, such as Ecotect or Geoweb 3D, can be used for vector data-based visibility analysis $[38,39]$. Given the increasing capability to run sophisticated $3 \mathrm{D}$ analysis, the misrepresentation of analytical processes and results is a real risk. Isovist research has, however, provided a way to overcome this [40]. The isovist is defined as the volume of space representing the visual field of an observer from a specified origin [41]. Originally conceptualised and proposed by Tandy, the isovist technique has been widely used to compute visibility and spatial analysis in the fields of architecture and geography [42]. By providing a description of the space "from inside', from the point of view of individuals, as they perceive it, interact with it, and move through it", isovist generation is an illuminating way of understanding a spatial environment [31]. Benedikt has introduced a set of analytic measurements of isovist properties to be applied to achieve quantitative descriptions of spatial environments [43]. Other researchers have built on this to define spatial openness as "the volume of free space measured from all internal observation points" [29]. In other words, spatial openness can be analysed by considering the 'visible volume' from a location, before it is simplified into an "isovist polyhedron" (see Figure 2 upper and lower left). Isovist fields are generated by producing multiple isovists at regular intervals within a defined space, then using the results to produce a field representing the sum attributes of the generated isovists $[41,44]$. Attributes represented by the fields can include metrics such as the isovist area and perimeter. 

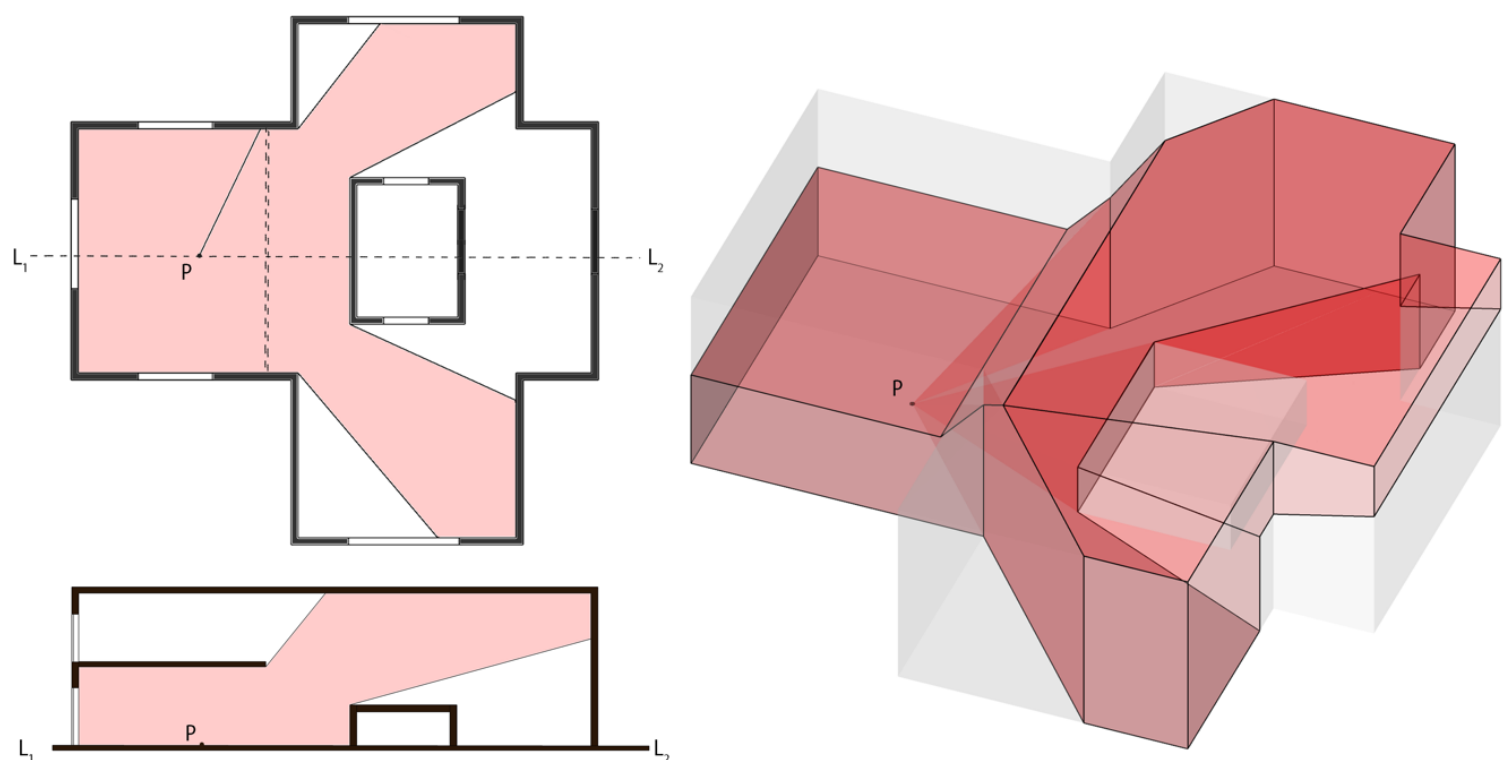

Figure 2. Isovist application in the interior built environment.

Isovist polyhedron in the plan view (upper left); and section view (lower left); the volume of the red polyhedron represents the viewing volume of point $\mathrm{p}$ and the area of the red polyhedron represents the viewing area (right)

Following this idea, the visibility analysis of a 3D interior built environment is much easier to compute $[45,46]$ and spatial openness can be measured using the viewing volume and/or the viewing area (see Figure 2 right). The viewing volume represents the visual volume available to people at a specific point in the space, whilst the viewing area represents the spatial superficial area of visual field and the amount of visual information that can be captured by a person within the space. While clearly interrelated, both are considered individually as metrics of spatial openness in 3D interior built environment in this paper. The greater the viewing volume or viewing area, the greater the spatial openness of the space. Recent developments have demonstrated a successful shift to truly 3D analysis using 3D voxel representations of the environment $[32,48]$. These quantitative methods are applicable in the built environment but have neither been fully developed nor tested in previous research on atria. The impact of different ceiling heights has also not been explored in the visibility analysis of atria.

\subsection{The evaluation of social learning spaces in educational buildings}

A key aspect of contemporary learning is social interaction. However, it is not simple to exclusively separate students' social activities from formal learning activities, particularly as both forms of peer-to-peer engagement often take place in the same physical settings [17]. Indeed, informal learning and socialising activities can be considered as a combined student experience in social learning spaces. Research on how to evaluate learning spaces, such as that by Bligh and Pearshouse [49], identifies such difficulties:

"Evaluating spaces in terms of pedagogic intent is difficult because such intent either was never explicit in the mind of the designer or evidence of the intent was not available to the evaluators." [50].

In order to evaluate learning spaces, seven models have been established: Demand model; Outcomes model; Satisfaction model; Scenario provision model; Activity support model; Spatial ecology model; and the Brand model [49]. Existing research on social learning spaces 
has generally examined student experience by utilising one or more of these models based on environmental behavioural theory [25,51-53]. There is some existing research exploring how the spatial attributes of social learning spaces can shape student activities through space syntax $[26,27,54,55]$. However, research into the social activities in atria, and how the influence of spatial openness impacts such activities in an educational setting, remains unexplored.

In summary, we can see that atrium spaces are becoming a common architectural typology in contemporary education institutions, particularly in dense urban environments. Typically, such spaces are designed to provide a social setting, for informal learning activities. Spatial openness has been described as an "important quality indicator" of spatial configurations [29], but, there is limited research on the spatial openness of atria spaces, and in particular, the potential impact this characteristic has on students' social learning activities in an education setting. With all this in mind, this study has two objectives:

1. To demonstrate a computational method to determine the spatial openness of different spaces within a multi-storey atrium space in an educational setting; and

2. To explore the impact spatial openness has on students' social learning activities within different areas of the atrium.

In order to achieve this, the viewing volume and viewing area (key measures of spatial openness) were simulated and measured for different spaces with different ceiling heights in an atrium. Then, student activities in the social learning spaces were recorded through observational analysis. The value of the viewing volume and the viewing area and the frequency of student activities occurring in the atrium were then compared to identify potential relationships. Finally, interviews were used to further explore the relationship between spatial openness and student activities.

\section{METHODOLOGY}

According to Environmental Behaviour Theory, there is a strong correlation between human behaviour and space [56]. In the context of this research, this relationship is explored through a case study and mixed methods design, including quantitative and qualitative methods. This methodology is graphically displayed in Figure 3 which outlines the primary research questions, data measured, and research methods used. Details are described in sections 2.2 and 2.3. The selected case study building is the Telford Exhibition Hall at the University of Nottingham, in the UK. Quantitative methods, including observation and QGIS, were employed to understand the student social and informal learning activities taking place within the Telford Exhibition Hall. Simulations and statistical analysis were employed to examine the spatial openness of the atrium, via measurements of viewing volume and viewing area. Finally, interviews are used to obtain an in-depth understanding of the occupants and their behaviours. 

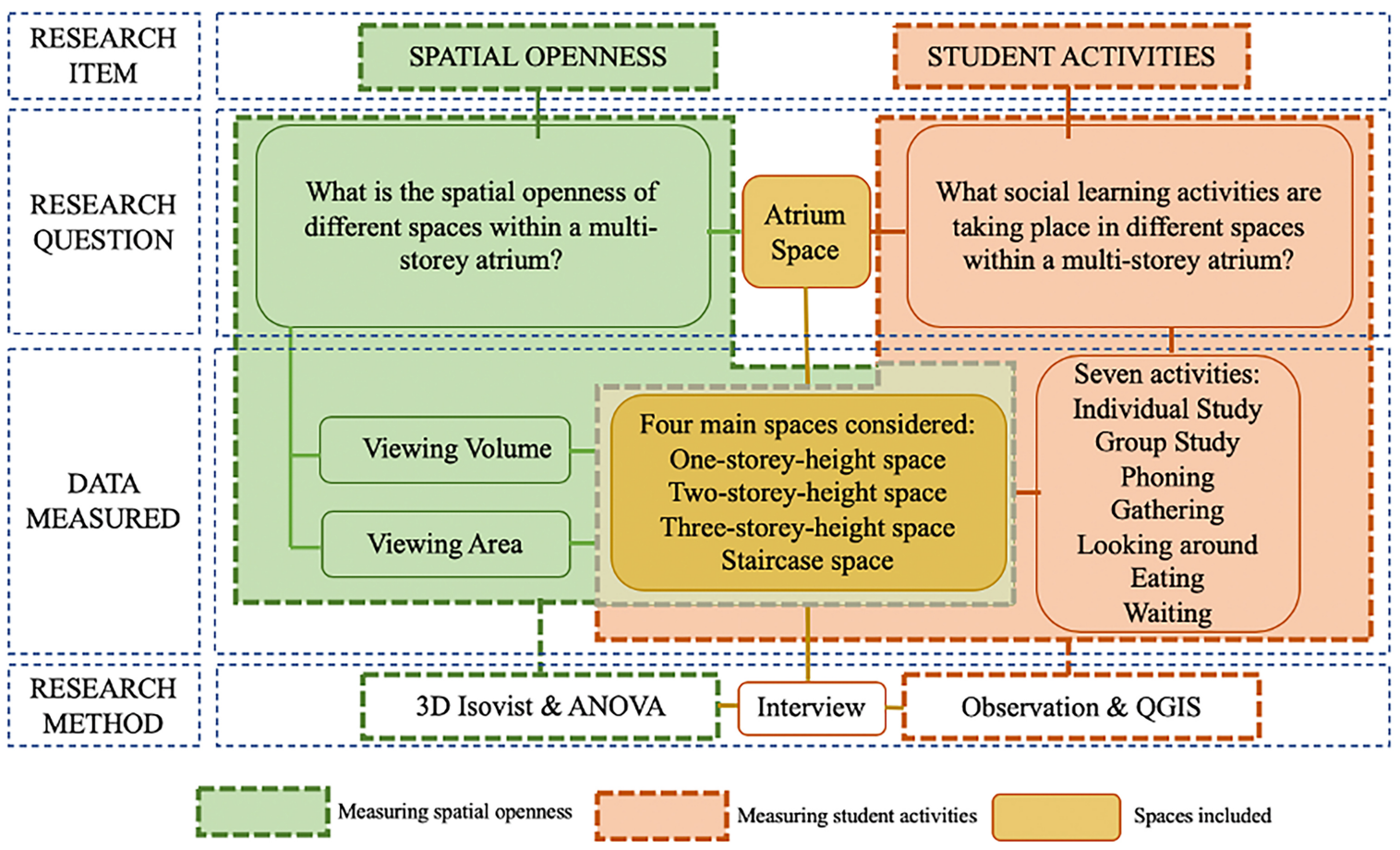

Figure 3. Research Design

\subsection{Description of the case study building}

The building chosen as a case study for this research was the Telford Exhibition Hall. This is a link space between the 'Coates Building' and the 'Pope Building' at the Faculty of Engineering, University of Nottingham, UK (see Figure 4). It has a hybrid functions as a circulation space, café, and multi-disciplinary social informal learning space. It was chosen for this study due to its accessibility to the research team, the opportunity to install monitoring equipment across several weeks, its architectural configuration accommodating an atrium space reflective of contemporary practice, and its role in hosting a range of social informal learning activities.

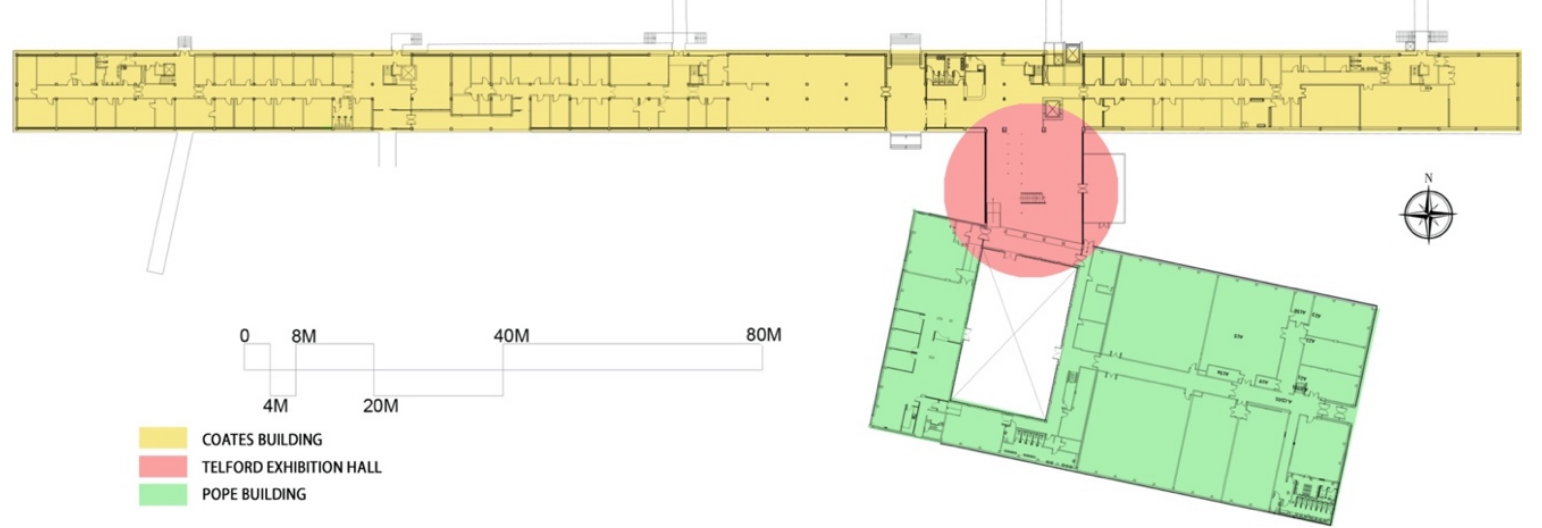

Figure 4. The Floor Arrangement of Coates Building, Telford Exhibition Hall and Pope Building Source: Estate Office at the University of Nottingham and adapted by Author

The Telford Exhibition Hall consists of a three-storey atrium with two partial upper floors accessible from a central staircase. The ground floor contains a small café, with hard floors. Large curtain-wall glazing spans the east and west façades, with the Coates Building to the north, and the Pope Building to the south (see Figure 5). Ceilings are timber planks, and the 
main mezzanine is hung from above by a tension system. On weekdays it is freely open to students, staff, and others whilst access at other times is controlled by university identification cards (which all students and staff have).

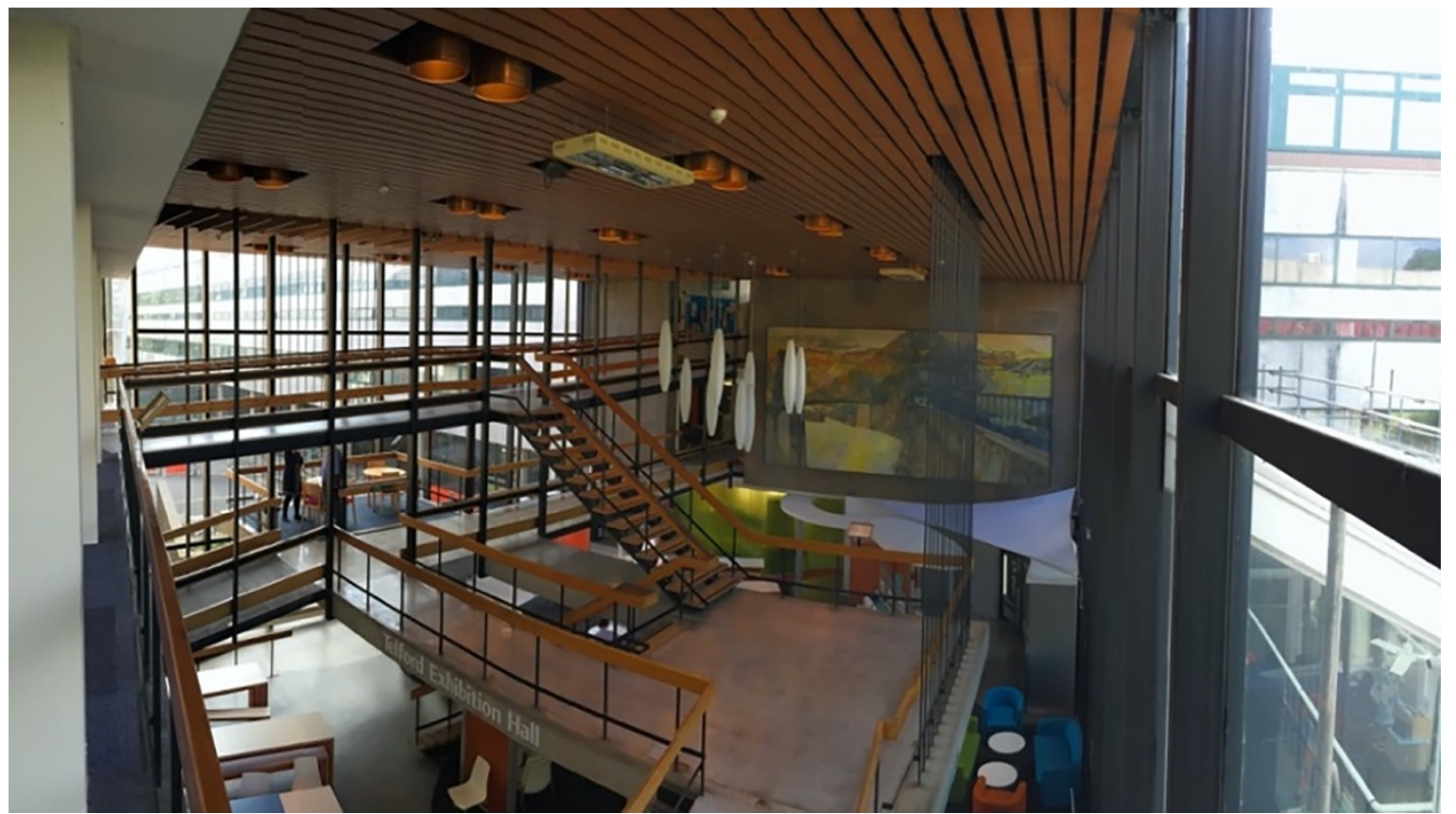

Figure 5. Telford Exhibition Hall, interior photo of mezzanines Source: Photo Taken by Author

As shown in Figure 6, the three-level atrium can be divided into four basic zones, organised around different ceiling heights. The yellow area on level A is a triple-height space; the purple area on level B is a double-height space; the red area is the staircase; and the green area spans across three levels and consists of single-height spaces.

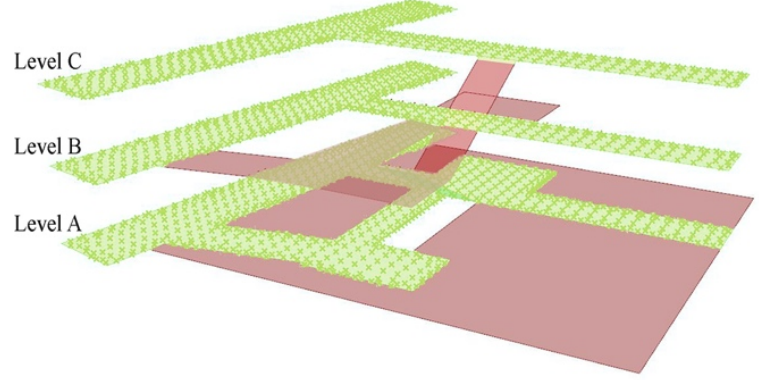

Standing Point on One-Storey-Height Space

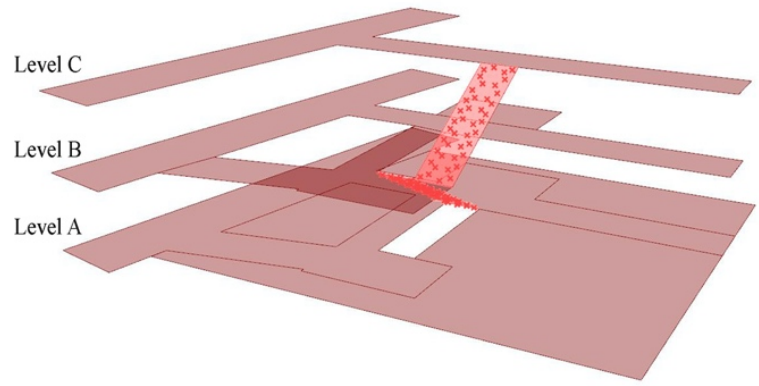

Standing Point on Staircase Space

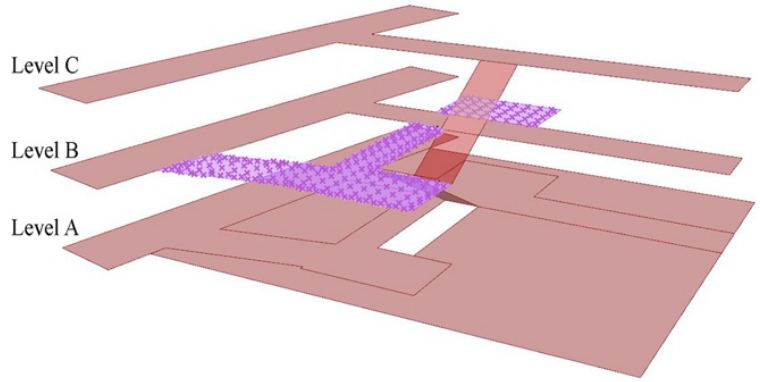

Standing Point on Two-Storey-Height Space

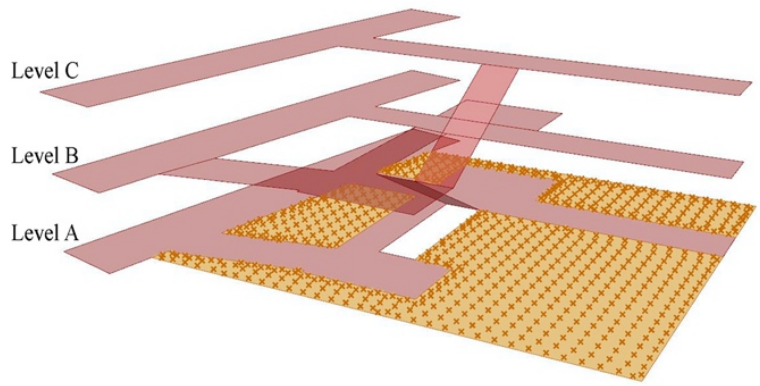

Standing Point on Three-Storey-Height Space

Figure 6. Telford Exhibition Hall: Organisation of space according to different ceiling heights 


\subsection{Measuring Spatial Openness: Simulation parameters and procedure}

The simulation of three-dimensional isovists was generated using Grasshopper software through an algorithm [57]. Inspired by the definition and the algorithm of a single isovist, the viewing volume (in green in Figure 7) visible from a given point $P$, together with a specification of the location of point P, were used as shown in Figure 7. For this research, an eye level of $1,700 \mathrm{~mm}$ above ground was chosen (see Figure $8 \mathrm{left}$ ). Some views will be obstructed by physical characteristics, such as the floors and stairs. Starting from the eye-level point of this imaginary person and ending at the Boundary Representation (BRep) which consists of the floors, walls, etc, numerous rays were drawn as shown in Figure 8 (middle). The total length of all the line segments was then calculated. At the same time, the minimum length, the maximum length and the average length, were generated and the line segments were set to start at a point and end at a hexagon. This determined the total volumes and basal areas of hexagonal pyramids (Figure 8 Right). The total volumes of hexagonal pyramids represent the viewing volume of the point of view of an individual. The average value of the viewing volumes measured from all internal observation points can be defined as one of the spatial openness indexes within the same ceiling height. Similarly, the total basal areas of hexagonal pyramids represent the viewing area. The average value of the viewing areas measured from all internal observation points, was also defined as one of the spatial openness indexes within the same ceiling height. The viewing volume is a measure of the space and the viewing area is a measure of the boundary. These two metrics are key to understanding spatial openness. However, the numerical value of the viewing volume and viewing area themselves have no absolute value. Instead they have a relative value when alternative spatial configurations are compared. According to 2D isovist analysis strategy [37], an isovist is a physical body bound by a closed polygon; hence it has geometric properties such as area and length of perimeter. Here, the total volumes and basal areas of hexagonal pyramids were calculated as two key elements to evaluate the $3 \mathrm{D}$ isovist.
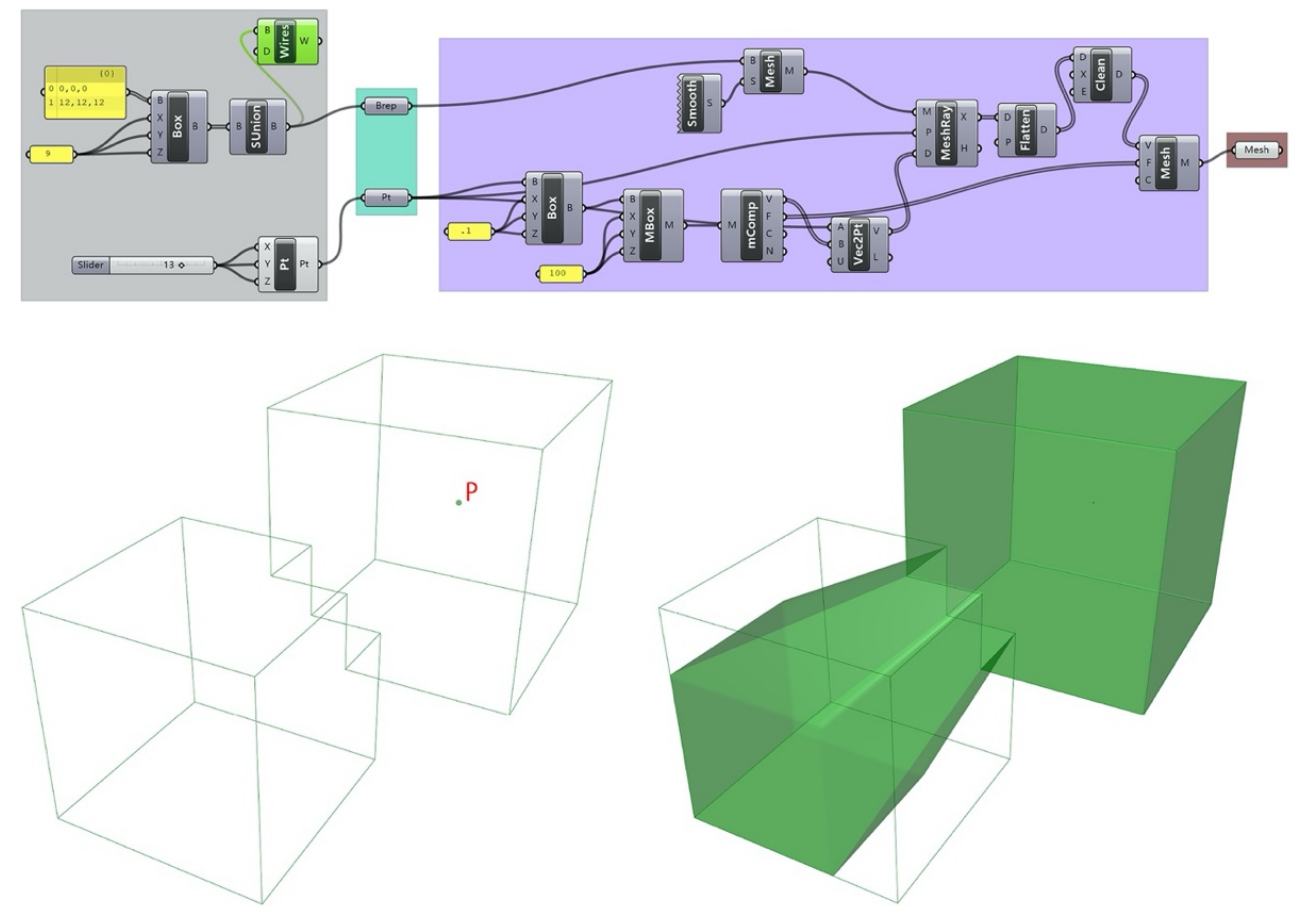

Figure 7. Methodological calculation and illustration for determining the space visible inside a given BRep file from a specific viewpoint. The top part of the figure presents an example for defining the boundary (BRep) and the viewpoint within it as determined by Grasshopper. [58] 

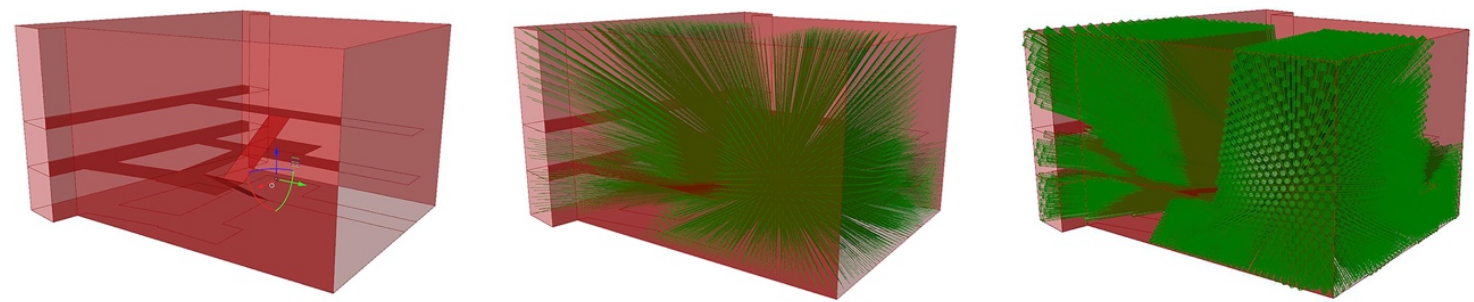

Figure 8. A point on the ground floor which represents a person who has an eye level 1,700mm above ground (Left); Rays starting at the point and ending at BRep (Middle); Hexagonal pyramid analysis (Right)

In order to minimise the error range, the location of a point is set to satisfy the requirements of the spatial limits. A $550 \mathrm{~mm} \times 550 \mathrm{~mm}$ grid is set across the floor spaces, to represent the different points where people can be located. To accommodate the edges of the space, for example the width of handrails around the mezzanines, a $200 \mathrm{~mm}$ offset is included to obtain clean grid points representing real user positions. An isovist analysis was run for each gridpoint in all of the spaces. In total, 3,332 points were calculated and analysed.

In order to justify the use of hexagonal pyramids to calculate the viewing volume and the viewing area, we can consider a point $(p)$ in a cube (see Figure 9). Starting from point $p$, a typical ray ends at the bottom of the cube $\left(p_{1}\right)$. If the hexagonal side length is $a$ and the length of $p-p_{1}$ is $h_{1}$, the basal area of hexagonal pyramids $\left(S_{1}\right)$ is equal to $(3 / 2) \times \sqrt{3} a_{1}^{2}$, and the volume of hexagonal pyramid $\left(V_{l}\right)$ is equal to $(1 / 2) \times \sqrt{3} a_{1}^{2} h_{l}$. The total viewing area (1) has a positive relationship with the square of hexagonal side length $\left(a_{i}^{2}\right)$ and the value of ' $n$ '. For best accuracy, the value of ' $a$ ' closest to zero and the value of ' $n$ ' tends to a positive infinity. In this case, the total viewing area approximately reaches the value of the superficial area of the cube. That means, no matter what the shape of the basal area is, the value of total viewing area has no significant impact on it.

$$
\begin{aligned}
& \text { Total viewing area } \begin{aligned}
\sum_{i=1}^{n} & \mathrm{~S}_{i}=\mathrm{S} 1+\mathrm{S} 2+\ldots+\mathrm{Sn} \\
& =(3 / 2) \times \sqrt{3}\left(\mathrm{a}_{1}{ }^{2}+\mathrm{a}_{2}{ }^{2}+\ldots+\mathrm{a}_{\mathrm{n}}{ }^{2}\right) \\
& =(3 / 2) \times \sqrt{3} \sum_{i=1}^{n} a_{i}{ }^{2}
\end{aligned}
\end{aligned}
$$

Similarly, the total viewing volume has a positive relationship with the square of hexagonal side length $\left(\mathrm{a}_{\mathrm{i}}{ }^{2}\right)$, the value of ' $n$ ', and the ' $h_{0}$ '. For best accuracy, the value of ' $a_{i}$ ' closest to zero and the value of ' $n$ ' tends to a positive infinity. In this case, the total viewing volume approximately reaches the volume of the cube. That means, no matter what the shape of the basal area is, the value of total viewing area has no significant impact on it. So effectively the hexagon was chosen for simplicity of calculation, although it could also be either a square or a circle.

$$
\text { Total Viewing volume } \begin{aligned}
\sum_{i=1}^{n} & \mathrm{~V}_{i}=\mathrm{V} 1+\mathrm{V} 2+\ldots+\mathrm{Vn} \\
& =(1 / 2) \times \sqrt{ } 3\left(\mathrm{a}_{1}{ }^{2} \mathrm{~h}_{1}+\mathrm{a}_{2}{ }^{2} \mathrm{~h}_{2}+\ldots+\mathrm{a}_{\mathrm{n}}{ }^{2} \mathrm{~h}_{\mathrm{n}}\right) \\
& =(1 / 2) \times \sqrt{3} \mathrm{~h}_{0} \sum_{i=1}^{n} a_{i}{ }^{2}
\end{aligned}
$$

' $p-p_{1}$ ' is the ray starting from $\mathrm{p}$ and ending at $p_{1}$. ' $p-p_{2}$ ' is a ray next to the ray ' $p-p_{1}$ '. In terms of the intersections within hexagonal volumes, due to the value of $p_{1-} p_{2}(3)$ approaching to zero, ideally, when the value of ' $n$ ' is closest to positive infinity, the value of ' $p_{1-} p_{2}$ ' is closest to zero. This means that the intersections within the hexagonal volumes is approaching zero.

$$
\mathrm{p}_{1}-\mathrm{p}_{2}=(1 / 2) \times \sqrt{3}\left(\mathrm{a}_{1}+\mathrm{a}_{2}\right) \rightarrow 0+
$$




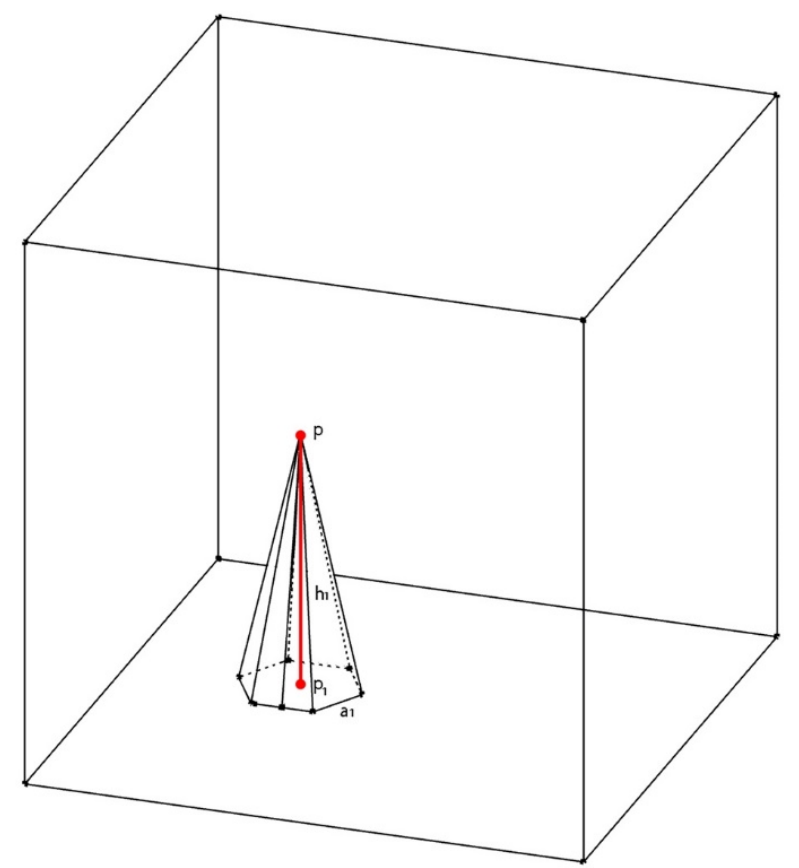

Figure 9. The use of a hexagonal pyramid to determine viewing volume and viewing area

The characters of the standing points presents sets of measurements: $\mathrm{X}$-axis, Y-axis, Z-axis, Volumes (V), Areas (A), Standard Deviation (SD), Minimum Length, Average Length, Maximum Length and Average (True) Length (see Table 1). The X, Y and Z-Axis represent the three point coordinates. Volumes and Areas represent the sum of volumes and basal areas of hexagonal pyramids, respectively, whilst Length is the length of the segment. The Average Length and Standard Deviation are calculated for different ceiling heights. The data is generated and transferred into MS Excel documents. The Analysis of variance (ANOVA) was used to examine the significant differences of different ceiling heights upon the mean volume, mean area and their standard deviation, respectively. This tool helped to inform the research through the collection of statistical models used to analyse the differences among group means and their associated procedures (such as "variation" among and between groups). The data of viewing volume and viewing area are imported into SPSS statistics software for further ANOVA analysis.

Table 1. Data collection example for the spatial elements of the Telford Exhibition Hall

\begin{tabular}{cccccccccc}
\hline $\begin{array}{c}\text { X- } \\
\text { Axis }\end{array}$ & Y-Axis & $\begin{array}{c}\text { Z- } \\
\text { Axis }\end{array}$ & V & A & SD & $\begin{array}{c}\text { Minimum } \\
\text { Length }\end{array}$ & $\begin{array}{c}\text { Average } \\
\text { Length }\end{array}$ & $\begin{array}{c}\text { Maximum } \\
\text { Length }\end{array}$ & $\begin{array}{c}\text { Average } \\
\text { (True) } \\
\text { Length }\end{array}$ \\
\hline$\{12375.0$ & 13449 & $1700.0\}$ & 3248.314 & 844.3935 & 844.3935 & 1700 & 6720 & 20985 & 6229 \\
$\{16917.0$ & 10077 & $1700.0\}$ & 4186.544 & 1002.238 & 1002.238 & 757 & 5155 & 20455 & 4428 \\
$\{14062.0$ & 9632 & $1700.0\}$ & 2630.451 & 737.6708 & 737.6708 & 1341 & 5999 & 19442 & 5569 \\
$\{3575.0$ & 9891 & $1700.0\}$ & 2961.451 & 763.9923 & 763.9923 & 856 & 4588 & 20499 & 3853 \\
$\{3090.0$ & 9835 & $1700.0\}$ & 3793.21 & 931.1944 & 931.1944 & 371 & 4286 & 20897 & 3488 \\
$\ldots$ & $\ldots$ & $\ldots$ & $\ldots$ & $\ldots$ & $\ldots$ & $\ldots$ & $\ldots$ & $\ldots$ & $\ldots$ \\
$\ldots$ & $\ldots$ & $\ldots$ & $\ldots$ & $\ldots$ & $\ldots$ & $\ldots$ & $\ldots$ & $\ldots$ & $\ldots$ \\
\hline
\end{tabular}

\subsection{Measuring Student Activities: Observations and Interviews}

In order to create better social informal learning spaces, it is imperative that designers, planners and managers understand what people actually do in such environments. This is because learning experiences range from structured, formal, teacher-led experiences to moments of less 
structured, peer-to-peer, informal or self-directed learning [59]. Student activities vary and can be classified based on both socialising and informal learning activities [61]. According to this classification, individual study and group study are informal learning activities whilst phoning, gathering, looking around, eating, and waiting are considered social activities. In this research these seven different activities were defined as such. Individual study activities were defined in two ways: 1) studying individually: students sitting down individually for a prolonged period of time for reading, writing, or using their laptop; and 2) intermittent exchange: whereby students convene for independent study that permits an occasional and improvised to-and-fro of questioning or commentary [25]. Group studying activities were defined as students' studying clearly in a group setting. Phoning activities were defined as students using their telephone for making a voice or video call. Gathering activities were defined as people gathering together for a clear purpose, such as volunteers gathering together for a training session, and clearly distinguished from more serendipitous encounters. That is, when you meet a friend or someone you know, but neither of you planned to meet. Looking around activities were defined as someone walking around without a rush or strong purpose. They seem unfamiliar with this space and keep looking around. Eating activities were defined as people eating or drinking. Different from gathering activities, waiting activities in this research were defined as two or three students, who meet together inside the atrium and then leave together. These activities clearly include a degree of perception and interpretation by the observer, and in this research are subjectively assessed.

Student distribution within the space objectively reflects the location of students when they undertake these behaviours within the space. In this research, the data on student distribution and activities was collected over a one-week period (from $8^{\text {th }}$ to $14^{\text {th }}$ of February 2018). Observations were captured using snapshot and gate counting. As the spaces of Telford Exhibition Hall are organised around a three-storey-height atrium, one capture point was discreetly selected as a vantage point inside for the monitoring the activities. The locus of the snapshot is located on the A floor in the corner of the Atrium (see Figure 10), which could capture the maximum allowable view. Panoramic photographs were used to capture broad and substantive views of the atrium space, and the activities within (see Figure 11). These were taken every two minutes across six hours ( $8 \mathrm{am}-10 \mathrm{am}$ in the morning, $12 \mathrm{pm}-2 \mathrm{pm}$ in the middle of the day, and $4 \mathrm{pm}-6 \mathrm{pm}$ in the afternoon). These parameters were determined by a two-week pilot study undertaken between the $11^{\text {th }}$ to $17^{\text {th }}$ and $25^{\text {th }}$ to $31^{\text {st }}$ of January 2018 . The pilot study was set up to test the optimum camera position and snapshot frequency to capture student behaviours. Photographs every one minute, two minutes and five minutes were trialled in the pilot study, resulting in every two minutes being chosen as the right balance between the number of shots and the details of the activities. 


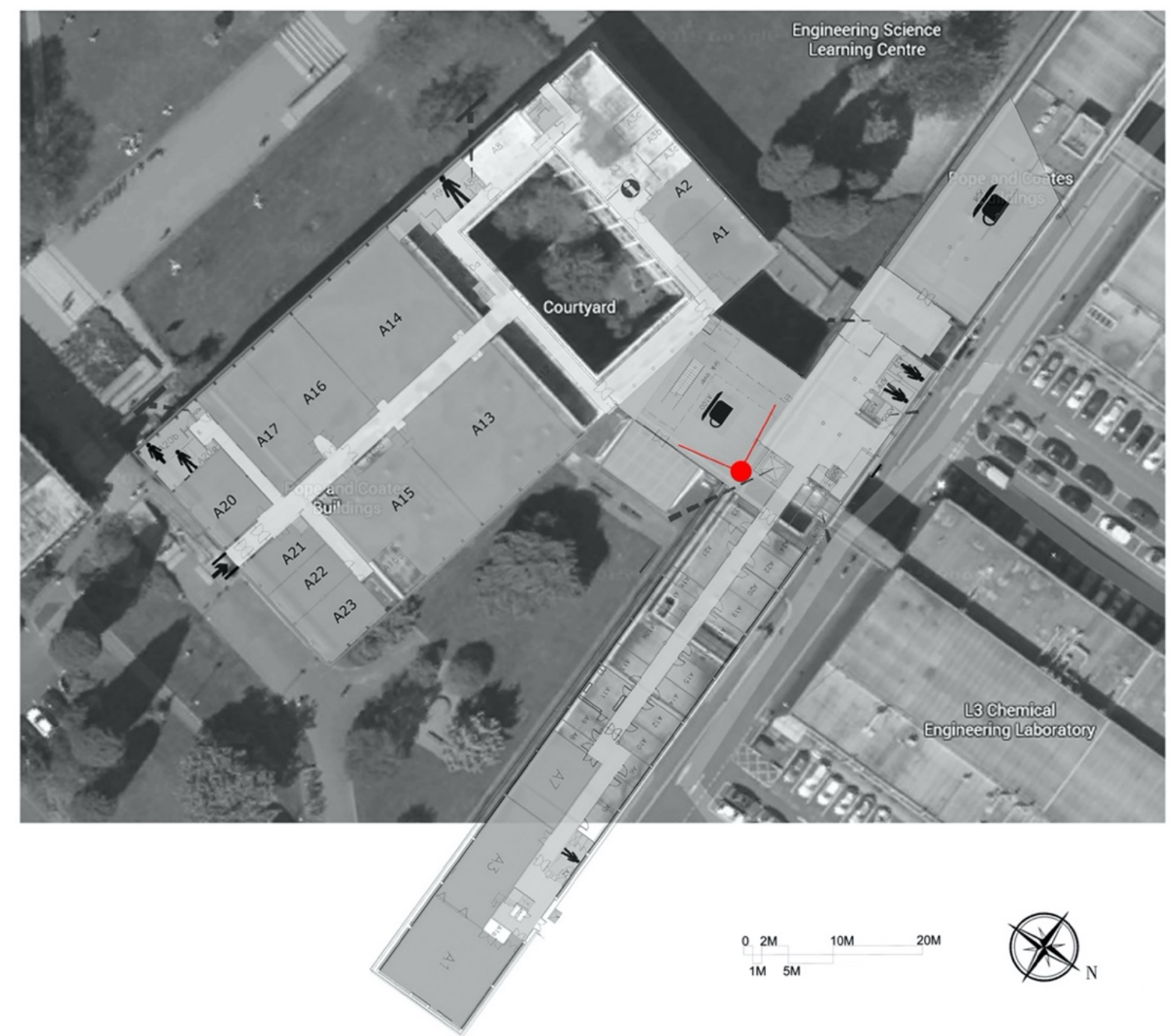

Figure 10. Vantage Point for observing the internal atrium of the Telford Exhibition Hall

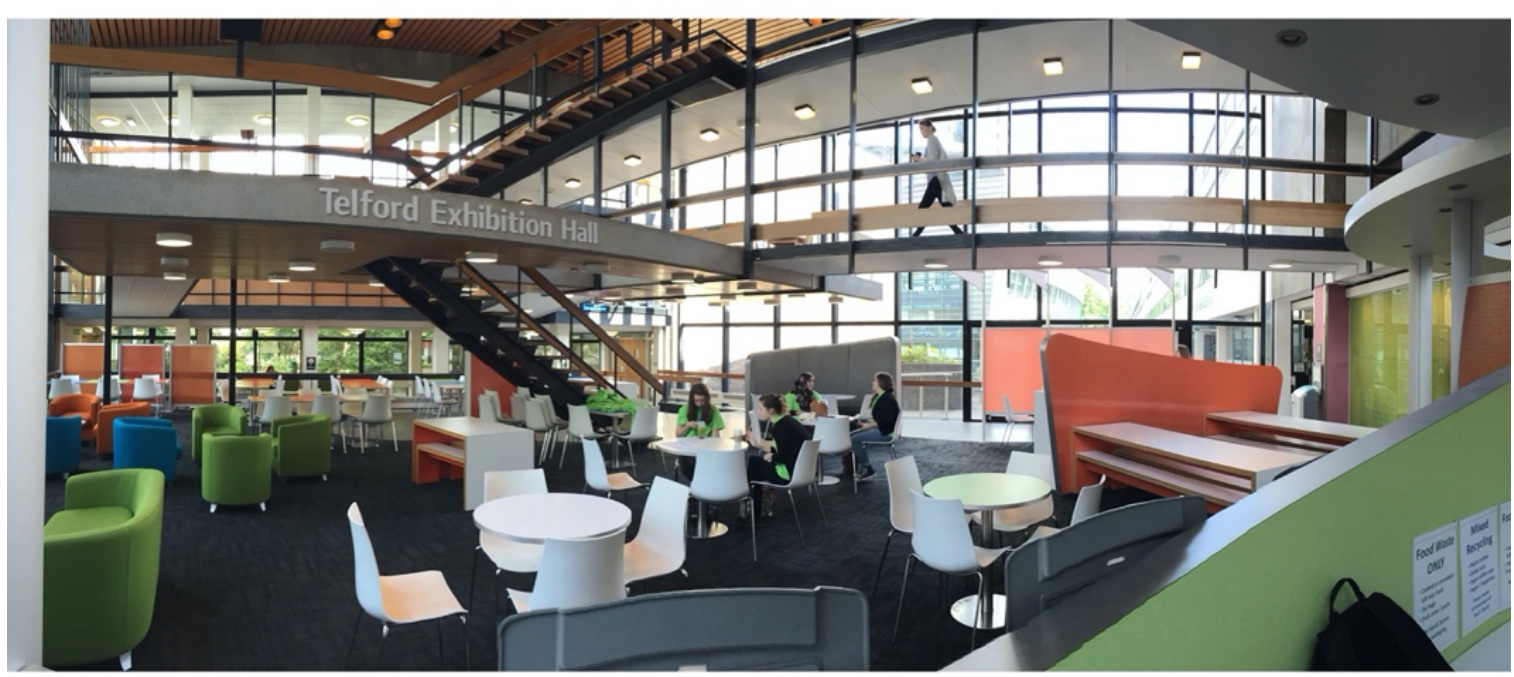



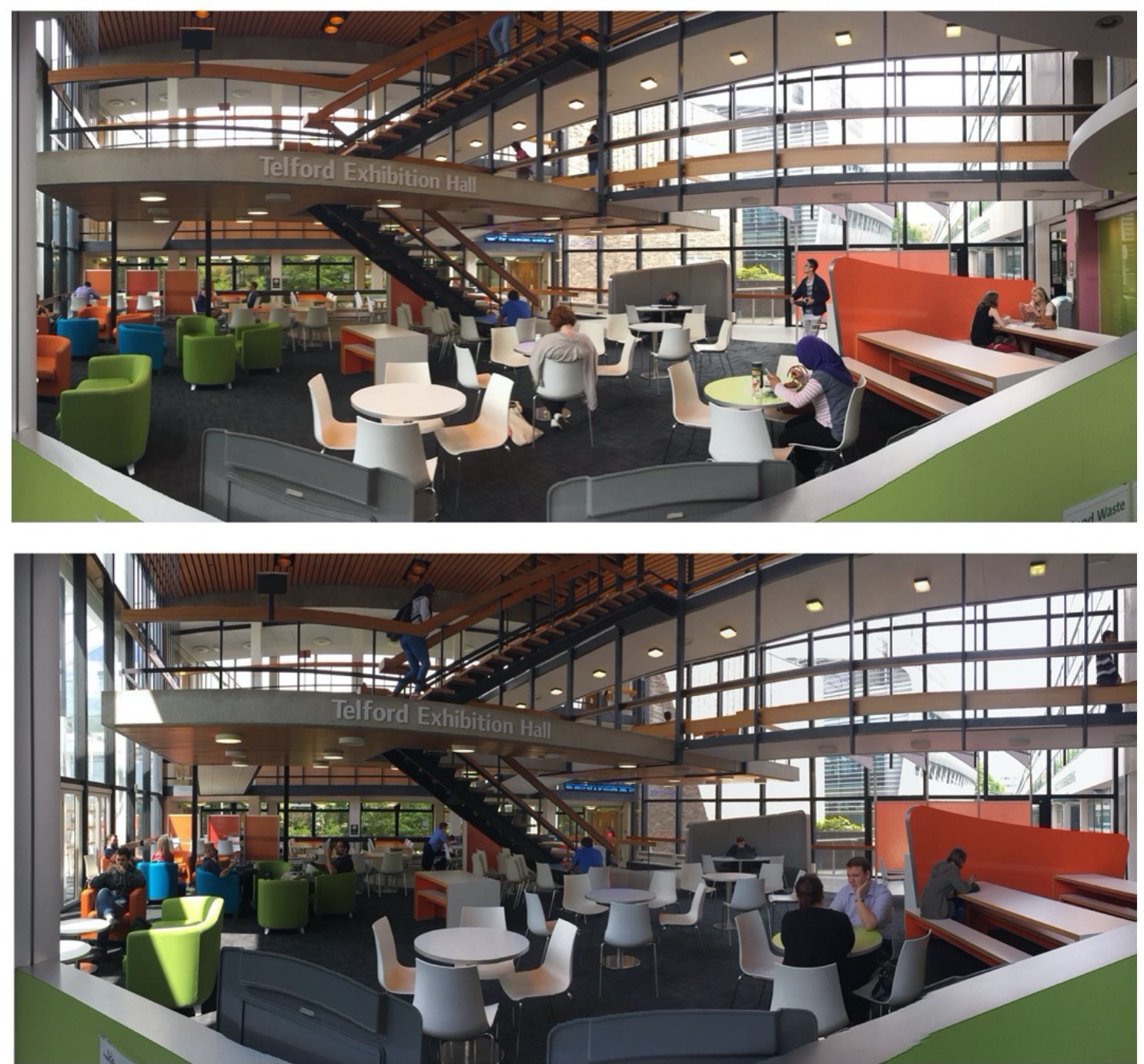

Figure 11. Panoramic views of individuals' activities in the Telford Exhibition Hall from the vantage point (the upper photo taken in the morning; the middle photo taken in the midday period; the lower photo taken in the afternoon) Source: Photo Taken by Author

In total, 900 pictures capturing 4,917 individuals were collected as primary data. Twelve individual activities were excluded due to difficulty in identifying the specific student activity being undertaken. In the photographs, the number of students, their locations in the plan and their types of activities were recorded and analysed. This data was analysed using QGIS Software, which has been widely used to analyse human behaviours in the built environment $[62,63]$. To ensure participant confidentiality and anonymity, the primary data collected was saved using online 360 network disks and then regenerated into mapping profiles and drawings.

In addition to observations, face-to-face semi-structured interviews were also conducted. Fifteen students using the space were individually interviewed. These students were informally approached, and the interviews covered three key topics: background information, frequency and activities of use of the space; and student perceptions of spatial openness in the atrium. All the records were scripted into Microsoft Word and analysed using NVivo software. A copy of the interview questions is outlined in Appendix A. 


\section{RESULTS}

\subsection{Viewing volume and viewing area}

The measured viewing volume and viewing area were divided into four categories according to the different ceiling heights as outlined in the methodology: one-storey-height space; twostorey-height space; three-storey-height space; and the staircase space. Table 2 indicates the mean value and standard deviation of the viewing volume and viewing area for each of these four spaces. The output of ANOVA analysis is shown in Table 3 and the Least Significant Difference (LSD) Multiple Comparisons are shown in Table 4.

Table 2. Description of the viewing volume $\left(\mathrm{m}^{3}\right)$ and viewing area of the Telford Exhibition Hall $\left(\mathrm{m}^{2}\right)$

\begin{tabular}{ccccc}
\hline Ceiling height & Mean Volume & SD & Mean Area & SD \\
\hline One-storey-height space & 3029.94 & 989.19 & 709.54 & 157.84 \\
Staircase space & 3214.12 & 287.71 & 951.03 & 81.60 \\
Two-storey-height space & 3255.71 & 373.46 & 869.30 & 79.96 \\
Three-storey-height space & 3229.11 & 1319.26 & 787.20 & 213.82 \\
\hline
\end{tabular}

Table 3. The output of ANOVA analysis (df: Degree of freedom; F: F value: Sig.: p value)

\begin{tabular}{ccc|c|c|c|c}
\hline & & Sum of Squares & df & Mean Square & F & Sig. \\
\hline \multirow{2}{*}{$\begin{array}{c}\text { Viewing } \\
\text { Volume }\end{array}$} & Between Groups & 6361552.764 & 3 & 2120517.588 & 2.884 & .035 \\
\cline { 2 - 7 } & Within Groups & 585300042.300 & 796 & 735301.561 & & \\
\cline { 2 - 7 } & Total & 591661595.100 & 799 & & & \\
\hline Viewing Area & Between Groups & 6507012.215 & 3 & 2169004.072 & 103.675 & .000 \\
\cline { 2 - 7 } & Within Groups & 16653306.290 & 796 & 20921.239 & & \\
\cline { 2 - 7 } & Total & 23160318.500 & 799 & & & \\
\hline
\end{tabular}

Table 4. LSD Multiple Comparisons Table

\begin{tabular}{|c|c|c|c|c|}
\hline $\begin{array}{l}\text { Dependent } \\
\text { Variable }\end{array}$ & (I) Ceiling Height Space & (J) Ceiling Height Space & Mean Difference (I-J) & Sig. \\
\hline \multirow{12}{*}{$\begin{array}{l}\text { Viewing } \\
\text { volume }\end{array}$} & \multirow[t]{3}{*}{ Staircase space } & One-storey-height space & $184.18854^{*}$ & .032 \\
\hline & & Two-storey-height space & -41.58303 & .628 \\
\hline & & Three-storey-height space & -14.98923 & .861 \\
\hline & \multirow[t]{3}{*}{ One-storey-height space } & Staircase space & $-184.18854 *$ & .032 \\
\hline & & Two-storey-height space & $-225.77157 *$ & .009 \\
\hline & & Three-storey-height space & $-199.17777 *$ & .020 \\
\hline & \multirow[t]{3}{*}{ Two-storey-height space } & Staircase space & 41.58303 & .628 \\
\hline & & One-storey-height space & $225.77157^{*}$ & .009 \\
\hline & & Three-storey-height space & 26.59380 & .757 \\
\hline & \multirow[t]{3}{*}{ Three-storey-height space } & Staircase space & 14.98923 & .861 \\
\hline & & One-storey-height space & $199.17777^{*}$ & .020 \\
\hline & & Two-storey-height space & -26.59380 & .757 \\
\hline \multirow{10}{*}{$\begin{array}{c}\text { Viewing } \\
\text { area }\end{array}$} & \multirow[t]{3}{*}{ Staircase space } & One-storey-height space & $241.49792 *$ & .000 \\
\hline & & Two-storey-height space & $81.73465^{*}$ & .000 \\
\hline & & Three-storey-height space & $163.83572 *$ & .000 \\
\hline & \multirow[t]{3}{*}{ One-storey-height space } & Staircase space & $-241.49792 *$ & .000 \\
\hline & & Two-storey-height space & $-159.76327 *$ & .000 \\
\hline & & Three-storey-height space & $-77.66219 *$ & .000 \\
\hline & \multirow[t]{3}{*}{ Two-storey-height space } & Staircase space & $-81.73465^{*}$ & .000 \\
\hline & & One-storey-height space & $159.76327 *$ & .000 \\
\hline & & Three-storey-height space & $82.10107^{*}$ & .000 \\
\hline & Three-storey-height space & Staircase space & $-163.83572 *$ & .000 \\
\hline
\end{tabular}




\begin{tabular}{ll|l} 
One-storey-height space & $77.66219^{*}$ & .000 \\
\hline Two-storey-height space & $-82.10107^{*}$ & .000 \\
\hline
\end{tabular}

In terms of viewing volume, there was a statistically significant difference between the different spaces as determined by one-way ANOVA $(\mathrm{F}(3,796)=2.884, \mathrm{p}=.035)$ (see Table $3)$. An LSD test revealed that the viewing volume was statistically significantly greater in the staircase space $\left(3214.12 \pm 287.71 \mathrm{~m}^{3}, \mathrm{p}=.032\right)$, the two-storey-height space $(3255.71 \pm 373.46$ $\left.\mathrm{m}^{3}, \mathrm{p}=.009\right)$, and the three-storey-height space $\left(3229.11 \pm 1319.26 \mathrm{~m}^{3}, \mathrm{p}=.020\right)$ compared to the one-storey-height space $\left(3029.94 \pm 989.19 \mathrm{~m}^{3}\right)$. There was no statistically significant difference between the viewing volume in the staircase space and the two-storey-height space $(\mathrm{p}=.628)$. There was no statistically significant difference between the viewing volume in the staircase space and three-storey-height space $(\mathrm{p}=.861)$. There was no statistically significant difference between the viewing volume in the two-storey-height space and the three-storeyheight space $(p=.757)$.

Surprisingly, the mean viewing volume in the three-storey-height space of the Telford Exhibition Hall $\left(3229.11 \mathrm{~m}^{3}\right)$ was not the greatest. Instead it was the two-storey-height space which had the greatest mean viewing volume $\left(3255.71 \mathrm{~m}^{3}\right)$. In addition, the differences in viewing volume in the three-storey-height space were significant $\left(\mathrm{SD}=1319.26 \mathrm{~m}^{3}\right)$. That is to say, the three-storey-height space is a dramatic place where people experience different perceptions of spatial openness.

In terms of the viewing area, there was a statistically significant difference between the groups as determined by one-way ANOVA $(\mathrm{F}(3,796)=103.675, \mathrm{p}=.000)$ (see Table 3 ). An LSD multiple comparison revealed that the viewing area in the one-storey-height space $(709.54 \pm$ $\left.157.84 \mathrm{~m}^{2}, \mathrm{p}=.000\right)$ was statistically the lowest while the viewing area in the staircase space $\left(951.03 \pm 81.60 \mathrm{~m}^{2}, \mathrm{p}=.000\right)$ was statistically significantly greater than the others. The viewing areas between different ceiling height spaces had a statistically significant difference (see Table 4).

The greater the viewing area is, the more information that can be captured by a person within the Telford Exhibition Hall. That is, the more information on BRep (like floors, walls, etc) can be noticed by the viewer. Again, the mean viewing area in the three-storey-height space of the Telford Exhibition Hall was not the greatest, compared with the others. As shown in Table 2, the staircase space had the greatest mean viewing area of $951.03 \mathrm{~m}^{2}$. However, the differences in viewing area in the three-storey-height space were most significant $\left(\mathrm{SD}=213.82 \mathrm{~m}^{2}\right)$.

\subsection{Distribution of student activities}

The observations captured seven types of the student activities in the Telford Exhibition Hall: phoning; individual study; looking around; waiting; gathering; group study; and eating. The distribution of student activities in the Telford Exhibition Hall was captured by snapshots and gate counting. The data was analysed by QGIS software and the total number and percentages of different activities occurring in different spaces are presented in Table 5. As a whole, the Telford Exhibition Hall is a typical blended social learning space, where $45.6 \%$ of the activities can be defined as informal learning, and $54.4 \%$ as social activities. The frequencies of phoning $(43.61 \%)$ and looking around activities $(56.32 \%)$ were the greatest in the staircase space, whilst the frequencies of individual study $(71.47 \%)$ and waiting $(71.54 \%)$ were greatest in the twostorey-height space. The frequencies of gathering (92.4\%), group study (58.10\%), and eating activities $(83.42 \%)$ were greatest in the three-storey-height space. 
Table 5. Measures of spatial openness and activity distribution in the Telford Exhibition Hall. The highlighted cells refer to the highest value recorded.

\begin{tabular}{|c|c|c|c|c|c|c|c|c|}
\hline & \multicolumn{2}{|c|}{$\begin{array}{c}\text { One-storey-height } \\
\text { Space }\end{array}$} & \multicolumn{2}{|c|}{ Staircase Space } & \multicolumn{2}{|c|}{$\begin{array}{c}\text { Two-storey-height } \\
\text { Space }\end{array}$} & \multicolumn{2}{|c|}{$\begin{array}{c}\text { Three-storey-height } \\
\text { Space }\end{array}$} \\
\hline $\begin{array}{l}\text { Mean viewing } \\
\text { volume }\end{array}$ & \multicolumn{2}{|c|}{$3029.94 \mathrm{~m}^{3}$} & \multicolumn{2}{|c|}{$3214.12 \mathrm{~m}^{3}$} & \multicolumn{2}{|c|}{$3255.71 \mathrm{~m}^{3}$} & \multicolumn{2}{|c|}{$3229.11 \mathrm{~m}^{3}$} \\
\hline $\begin{array}{c}\text { Mean viewing } \\
\text { area }\end{array}$ & \multicolumn{2}{|c|}{$709.54 \mathrm{~m}^{2}$} & \multicolumn{2}{|c|}{$951.03 \mathrm{~m}^{2}$} & \multicolumn{2}{|c|}{$869.30 \mathrm{~m}^{2}$} & \multicolumn{2}{|c|}{$787.20 \mathrm{~m}^{2}$} \\
\hline $\begin{array}{l}\text { Viewing } \\
\text { volume SD }\end{array}$ & \multicolumn{2}{|c|}{$989.19 \mathrm{~m}^{3}$} & \multicolumn{2}{|c|}{$287.71 \mathrm{~m}^{3}$} & \multicolumn{2}{|c|}{$373.46 \mathrm{~m}^{3}$} & \multicolumn{2}{|c|}{$1319.26 \mathrm{~m}^{3}$} \\
\hline $\begin{array}{l}\text { Viewing area } \\
\text { SD }\end{array}$ & \multicolumn{2}{|c|}{$157.84 \mathrm{~m}^{2}$} & \multicolumn{2}{|c|}{$81.60 \mathrm{~m}^{2}$} & \multicolumn{2}{|c|}{$79.96 \mathrm{~m}^{2}$} & \multicolumn{2}{|c|}{$213.82 \mathrm{~m}^{2}$} \\
\hline Activity & $\begin{array}{c}\text { No. of } \\
\text { students }\end{array}$ & $\begin{array}{c}\text { Percent } \\
(\%)\end{array}$ & $\begin{array}{c}\text { No. of } \\
\text { student } \\
\text { s }\end{array}$ & $\begin{array}{c}\text { Percent } \\
(\%)\end{array}$ & $\begin{array}{c}\text { No. of } \\
\text { students }\end{array}$ & $\begin{array}{c}\text { Percent } \\
(\%)\end{array}$ & $\begin{array}{c}\text { No. of } \\
\text { students }\end{array}$ & $\begin{array}{c}\text { Percent } \\
(\%)\end{array}$ \\
\hline Phoning & 14 & $3.37 \%$ & 181 & $43.61 \%$ & 88 & $21.21 \%$ & 132 & $31.81 \%$ \\
\hline Individual study & 154 & $11.94 \%$ & 0 & 0 & 922 & $71.47 \%$ & 214 & $16.59 \%$ \\
\hline Looking around & 49 & $25.79 . \%$ & 107 & $56.32 \%$ & 0 & 0 & 34 & $17.89 \%$ \\
\hline Waiting & 28 & $21.54 \%$ & 0 & 0 & 93 & $71.54 \%$ & 9 & $6.92 \%$ \\
\hline Gathering & 0 & 0 & 0 & 0 & 38 & $7.60 \%$ & 462 & $92.40 \%$ \\
\hline Group study & 88 & $9.31 \%$ & 123 & $13.02 \%$ & 185 & $19.58 \%$ & 549 & $58.10 \%$ \\
\hline Eating & 29 & $2.02 \%$ & 29 & $2.02 \%$ & 180 & $12.54 \%$ & 1197 & $83.42 \%$ \\
\hline
\end{tabular}

\section{DISCUSSION}

\subsection{Relationship between spatial openness, waiting and individual study in the two-storey- height space.}

The simulations demonstrated that the mean viewing volume in the two-storey-height space was the highest. This space also has the second highest viewing area, a further measure of spatial openness (Table 5). Based on observations, over $71 \%$ of waiting activities took place in this space. It is suggested that students preferred to wait for their friends on this mezzanine space, next to the staircase, as it provides a significant sense of spatial openness. Indeed, in an interview one student noted that:

“...it's just a good point [for] meeting people because...whatever floor you are on, you can kind of spot, like, bigger areas... You can find people who are in this area."

Observational analysis suggested that students regularly waited for their friends on the platform next to the staircase. Standing on level B within the two-storey-height space, they were more likely to be seen by others. The mean viewing volume as an individual figure has little value, but its value is apparent as a comparative metric. Compared with the other spaces, the twostorey-height space provides a more open feeling as well as good visual access to the entirety of the atrium.

Meanwhile, over $71 \%$ of the individual study activities were also observed in the two-storeyheight space, also located on the floor B. However, in this instance, it is suggested the frequency of individual study in this space is more related to its functional arrangement than the viewing volume. Level B also includes a small but dedicated studying space, with two 
tables. This is perched above the busier ground floor spaces, limiting footfall past the tables, and thus minimising noise and distractions.

\subsection{Relationship between spatial openness and looking around on the staircase.}

The mean viewing area on the staircase space was the highest of the four areas studied. This demonstrates that the visual field on the staircase space was the highest. That is to say, students capture more spatial information here than in the other spaces in the atrium. The staircase space is mainly functional, used for vertical movement between the three floors. As such, it has no space for furniture, which means there is limited physical opportunities for students to study, wait, or gather with peers. Subsequently, no observations of these activities were captured. However, as the space with the greatest viewing area, it is ideal for capturing the most visual information and the highest number of looking around activities were observed here $(56 \%)$. As one student noted:

"Yeah, I do like it though, especially when you are at the top and you can see down...you know, look downstairs."

This means that the two activities with the greatest desire for students to 'see and be seen' (that is, looking around and waiting), were observed most frequently in spaces with the highest viewing area or viewing volume, both measures of spatial openness. In addition, there is a three-storey high painting located in the northeast of the atrium which acts a visual focal point for both students and visitors. This is best viewed from the staircase, and the two-storey height space. Such findings are consistent with the spatial benefits of atria identified in the literature - both generally, and specifically in terms of educational institutions. That is, atria provide visibility and visual access in multiple directions, allowing occupants to spatially orientate themselves in terms of their relationship to the building, its activities and to other occupants [14]. As Newton notes in a discussion on vertical schools in Australian cities:

"This movement across levels [in an atrium] makes learning visible, by providing glimpses into different learning environments...An atrium also helps with orientation and offers alternative social spaces to make up for the reduced connection to outdoor areas. "[64]

\subsection{Relationship between the standard deviations of the mean viewing volume and viewing area and gathering and group study activities in the three-storey-height space.}

Surprisingly, despite having the highest ceiling height, the three-storey space in the Telford Exhibition Hall did not have the greatest mean viewing volume or viewing area. However, the statistical analysis showed that the standard deviations of both the mean viewing volume and viewing area were the greatest in this space by a significant margin, being $1,319.26 \mathrm{~m}^{3}$ and $213.82 \mathrm{~m}^{2}$ respectively (see Table 2 ). This indicates that the diversity of viewing volume and viewing area is the highest in this space. Meanwhile, from the observational analysis, it can be seen that gathering $(92.4 \%)$, eating $(83.42 \%)$ and group study $(58.10 \%)$, occurred more frequently occurring in the three-storey-height space of the atrium.

It is likely these activities were also influenced by a variety of moderating factors that have not been directly measured in this study. These include furniture, lighting, acoustics, materials, etc. In particular, eating is popular in this space due to the proximity to the café and vending machines at level A. However, the interviews suggested that spatial openness played a role in some students' choice of activities in this space. For instance, one student responded that they 
considered, that the spatial and visual characteristics of the space had no bearing on how they used it:

\section{"I think [the spatial openness] doesn't influence it [my activities]."}

However, other students acknowledged the diversity of spatial openness available to them in the three-storey space, and how it impacted on their activities:

"[I'm using the three-storey space] because it's more open, and has more choice."

"I think personally I prefer to sit someplace with a low ceiling height. If I move around the [Telford Exhibition Hall] or something like that... then I prefer open spaces with higher ceilings. That is my preference."

To some extent, this diversity of spatial openness in the three-storey space indicates an inclusivity that allows different people to experience and undertake different activities within the space in different ways. Other research has shown that flexibility and diversity is important in social informal learning spaces in a number of ways. These include the flexibility of furniture allowing students to adapt their physical environment to different preferences and tasks, the desire for a mixture of privacy and openness, quietness and spaces for more animated conversations $[18,25]$. This research extends and complements existing research by suggesting that the diversity of spatial openness can also have an influence on student activities, and in particular, activities that require a level of social interaction such as gathering and group study.

\section{CONCLUSIONS}

With increasing urbanisation and the densification of cities, vertical education institutions are likely to become more common place $[55,65,66]$. Indeed, burgeoning inner-city populations require education facilities, and with increasing costs of land, low-rise schools and universities are neither economically nor sustainably feasible in many high-density environments. The multi-storey education buildings emerging increasingly use atria as an architectural strategy to provide social-informal learning spaces, but there is limited research on how the spatial qualities of these atria impact student behaviour and activities. This research attempts to fill this gap, by using a methodology that combines spatial simulation, observational analysis and student interviews.

The methodology itself contributes to the field by providing a mechanism to evaluate the spatial openness of an atrium through the use of parametric tools. The total volume and basal area of hexagonal pyramids are measured from multiple points within an atrium, representing the position of an occupant - in this case a student. Total volume represents the viewing volume, the visual volume available to a person at a specific point within a space. The total basal area is a measurement of the viewing area, representing how much information can be visually captured by a person within the space. Viewing volume and viewing area are interrelated but independent ways of measuring a space's spatial openness. ANOVA analysis was used to statistically interpret the data, allowing for a comparison with observational analysis of student behaviours in the space and semi-structured interviews with students.

The application of these methods was used to understand the Telford Exhibition Hall, a threestorey atrium and social informal learning space at the University of Nottingham, UK. The results showed that the two-storey space in the atrium had the highest mean viewing volume, whilst the staircase had the highest mean viewing area - thus both had a relatively high spatial 
openness in comparison with the other spaces. Meanwhile, the three-storey-height space had the greatest standard deviation of mean viewing volume and viewing area, and thus the most diverse spatial openness. Observations showed that waiting $(71.54 \%)$ and individual study $(71.47 \%)$ activities were the highest in the two-storey space, looking around (56.32\%) was the highest in the staircase space, and gathering (92.40\%), group study (58.10\%) and eating $(83.42 \%)$ were most frequent in the three-storey space. These results suggest that the spatial openness can have an impact on student activities. In particular, two main findings are highlighted as valuable for those who research or design such spaces:

1. Greater spatial openness (i.e. higher viewing volume and/or viewing area) can promote a sense of 'see' and 'be seen' for students and occupants, and thus facilitate more waiting and looking around activities. Higher levels of spatial openness also enable students to visually orientate themselves, see others and their surrounding activities, and to be seen by friends and peers in what is often a complex building typology.

2. The diversity of spatial openness within a particular space or zone may influence the frequency of student activities that require social interactions, such as gathering and group study. A higher diversity of spatial openness provides a flexibility of spatial experience, allowing different students to inhabit the space in different ways, depending on mood, tasks, and experiences. Research has shown that flexibility is important in social learning spaces, in terms of layout and furniture for instance $[18,25]$. Here it is suggested that such flexibility can also be considered important in terms of spatial openness. The 'stacked floorplate' model of multi-storey buildings, where every floorplate is essentially the same, has been widely criticised for failing to provide the diverse spatial experiences that are more commonly experienced in low-rise buildings, and the city as a whole [66-68]. This research here supports this notion, suggesting that the design of multi-storey education buildings with atria would benefit from a diversity of spatial openness, to foster students' informal and social learning activities.

This study does, however, have some limitations. There are other characteristics besides spatial openness that clearly influence student activities. These include the furniture layout and design, location of the café, access to technology, visual and thermal comfort, colour, ambience, acoustics, and more. These moderating factors were not directly measured in this research due to the specific focus on spatial openness. Future research should seek to layer in some of these other factors. For instance, triangulating the measurements of the environmental characteristics of an atrium, with its spatial openness and observations of student activities. In addition, this research focussed on a three-storey atrium, yet taller atria are increasingly commonplace in multi-storey commercial buildings around the world and are likely to emerge in future taller educational institutions. The methodology outlined here can be used to examine student social and informal learning activities in these more vertiginous spaces, to examine the influence of greater heights. This study uses the metrics of viewing volume and viewing area as measures of spatial openness. These are interrelated, but it is not clear whether the subtle differences between them (i.e. one being a measure of visible volume, and the other a measure of visible area) can influence activities or the perception of space. Likewise, the study here suggests that the diversity of spatial openness can influence the frequency of social activities such as group study and gathering. However, there would be value in further studies comparing such findings to activities in atria with less diversity of spatial openness. Finally, further research could explore more nuanced characteristics of student behaviours in atria spaces, including length of stay, and spatial satisfaction. Such research is important, especially given the clear trend towards multi-storey education institutions in cities around the world. 


\section{ACKNOWLEDGEMENTS}

This research was funded by the China Scholarship Council and the authors would also like to thank the University of Nottingham for supporting the research. We would like to extend a special thanks to Prof. Charles Crook and Prof. Mike Neary who provided their constructive feedback on initial drafts of the paper. We would also like to acknowledge the volunteers who helped us to collect data and record student behaviours, as without them this research would not have been possible. Finally, we would like to thank the six reviewers who generously provided detailed feedback to help refine and improve the paper.

\section{REFERENCES}

[1] M.J. Bednar, The new atrium, McGraw-Hill Build. Types Ser. (1986).

[2] C. Willis, Form Follows Finance: Skyscrapers and Skylines in New York, 1995. https://books.google.co.uk/books?hl=en\&lr=\&id=8ITT7GXSQnIC\&oi=fnd\&pg=PA69 $\& d q=$ Form + Follows + Finance $\&$ ots $=$ dsK3Rct $1--\& s i g=$ ayC7LfKIihRuYm4cnc4bBFiZxw\&redir_esc $=\mathrm{y} \# \mathrm{v}=$ onepage \&q$=$ Form Follows Finance $\& \mathrm{f}=$ false (accessed January 31, 2020).

[3] P. Oldfield, D. Trabucco, A. Wood, Five energy generations of tall buildings: An historical analysis of energy consumption in high-rise buildings, J. Archit. 14 (2009) 591-613. https://doi.org/10.1080/13602360903119405.

[4] W.Y. Hung, W.K. Chow, A review on architectural aspects of atrium buildings, Archit. Sci. Rev. 44 (2001) 285-295. https://doi.org/10.1080/00038628.2001.9697484.

[5] S. Sharples, D. Lash, Daylight in atrium buildings: A critical review, Archit. Sci. Rev. 50 (2007) 301-312. https://doi.org/10.3763/asre.2007.5037.

[6] B. Chen, J. Kang, Acoustic comfort in shopping mall atrium spaces - a case study in sheffield meadowhall, Archit. Sci. Rev. 47 (2004) 107-114. https://doi.org/10.1080/00038628.2004.9697033.

[7] E.D. Douvlou, Climatic responsive design and occupant comfort: the case of the atrium building in a Mediterranean climate, (2004).

[8] I. Danielski, G. Nair, A. Joelsson, M. Fröling, Heated atrium in multi-storey apartment buildings, a design with potential to enhance energy efficiency and to facilitate social interactions, Build. Environ. 106 (2016) 352-364. https://doi.org/10.1016/j.buildenv.2016.06.038.

[9] T.X. Qin, Y.C. Guo, C.K. Chan, W.Y. Lin, Numerical simulation of the spread of smoke in an atrium under fire scenario, Build. Environ. 44 (2009) 56-65. https://doi.org/10.1016/j.buildenv.2008.01.014.

[10] L. Moosavi, N. Mahyuddin, N. Ghafar, Atrium cooling performance in a low energy office building in the Tropics, a field study, Build. Environ. 94 (2015) 384-394. https://doi.org/10.1016/j.buildenv.2015.06.020.

[11] W.Y. Hung, W.K. Chow, A review on architectural aspects of atrium buildings, Archit. Sci. Rev. 44 (2001) 285-295. https://doi.org/10.1080/00038628.2001.9697484.

[12] J.H. Lee, Journal of Asian Architecture and Building Engineering Identifying spatial meanings of atria in built environment and how they work Identifying spatial meanings of atria in built environment and how they work, (2019). https://doi.org/10.1080/13467581.2019.1627216.

[13] M. Kazemzadeh, F. Sheikh Asadi, The New Attention to Atrium for Creating Sustainable Townscape, J. Civ. Eng. Urban. J. J. Civ. Eng. Urban. 4 (2014) 98-102. http://www.ojceu.ir/main/ (accessed September 25, 2019). 
[14] A. Kusumowidagdo, A. Sachari, P. Widodo, Visitors' perceptions on the important factors of atrium design in shopping centers: A study of Gandaria City Mall and Ciputra World in Indonesia, Front. Archit. Res. 5 (2016) 52-62. https://doi.org/10.1016/j.foar.2015.11.003.

[15] J. Yunus, S.S. Ahmad, A. Zain-Ahmed, Analysis of atrium's architectural aspects in office buildings under tropical sky conditions, CSSR 2010 - 2010 Int. Conf. Sci. Soc. Res. (2010) 536-541. https://doi.org/10.1109/CSSR.2010.5773836.

[16] A. Adams, D. Theodore, E. Goldenberg, C. McLaren, P. McKeever, Kids in the atrium: Comparing architectural intentions and children's experiences in a pediatric hospital lobby, Soc. Sci. Med. 70 (2010) 658-667. https://doi.org/10.1016/j.socscimed.2009.10.049.

[17] P. Jamieson, The serious matter of informal learning, Plan. High. Educ. 37 (2009) 8. http://www.scup.org/PHE.

[18] S. McDaniel, Every Space is a learning space, BWBR - Informal Learn. Spaces. (2014) 6. http://www.bwbr.com/wp-content/uploads/2016/10/Every-Space-Is-ALearning-Space-WP.pdf (accessed July 3, 2019).

[19] R. Saxon, Atrium buildings: development and design, 1983. http://chrisboudy.com/atrium-buildings-development-and-design-high-resolution-pdfrichard-saxon.pdf (accessed May 30, 2019).

[20] A. Harrison, Design for the Changing Educational Landscape, 2014. https://doi.org/10.4324/9780203762653.

[21] M. Weaver, Exploring conceptions of learning and teaching through the creation of flexible learning spaces: the learning gateway - a case study, New Rev. Acad. Librariansh. 12 (2006) 109-125. https://doi.org/10.1080/13614530701330414.

[22] Ørestad college - public high school in copenhagen $\mid 3 \mathrm{xn}$ architects $\mid 3 \mathrm{XN}$, (n.d.). https://3xn.com/project/orestad-college (accessed May 26, 2020).

[23] P. Lourenço, M.D. Pinheiro, T. Heitor, Light use patterns in Portuguese school buildings: User comfort perception, behaviour and impacts on energy consumption, J. Clean. Prod. 228 (2019) 990-1010. https://doi.org/10.1016/j.jclepro.2019.04.144.

[24] D. Holley, C. Dobson, Encouraging student engagement in a blended learning environment: The use of contemporary learning spaces, Learn. Media Technol. 33 (2008) 139-150. https://doi.org/10.1080/17439880802097683.

[25] C. Crook, G. Mitchell, Ambience in social learning: Student engagement with new designs for learning spaces, Cambridge J. Educ. 42 (2012) 121-139. https://doi.org/10.1080/0305764X.2012.676627.

[26] A.P. Vieira, M. Krüger, Space codes in architectural teaching and learning, n.d.

[27] K. Sailer, The spatial and social organisation of teaching and learning: The case of Hogwarts School of Witchcraft and Wizardry, n.d. http://www.merriamwebster.com/dictionary/learning (accessed September 29, 2019).

[28] M. Llobera, Extending GIS-based visual analysis: The concept of visualscapes, Int. J. Geogr. Inf. Sci. 17 (2003) 25-48. https://doi.org/10.1080/713811741.

[29] D. Fisher-Gewirtzman, I.A. Wagner, Spatial openness as a practical metric for evaluating built-up environments, Environ. Plan. B Plan. Des. 30 (2003) 37-49. https://doi.org/10.1068/b12861.

[30] $\mathrm{X}$. Wu, The design qualities and spatial organisation for higher education informal learning spaces, 2018. http://eprints.nottingham.ac.uk/52362/ (accessed June 26, 2019).

[31] A. Turner, M. Doxa, D. O'sullivan, A. Penn, From isovists to visibility graphs: a methodology for the analysis of architectural space, (n.d.). https://doi.org/10.1068/b2684. 
[32] D. Fisher-Gewirtzman, A. Shashkov, Y. Doytsher, Voxel based volumetric visibility analysis of urban environments, Surv. Rev. 45 (2013) 451-461. https://doi.org/10.1179/1752270613y.0000000059.

[33] T. Varoudis, S. Psarra, Beyond two dimensions: Architecture through threedimensional visibility graph analysis, (n.d.). http://joss.bartlett.ucl.ac.uk (accessed May 30, 2019).

[34] B. Hillier, Space is the machine, 1997. https://doi.org/10.1016/S0142-694X(97)898547.

[35] Bill Hillier; Julienne Hanson, The social logic of space, Landsc. Urban Plan. 13 (1986) 247-249. https://doi.org/10.1016/0169-2046(86)90038-1.

[36] N. Saruyama, T. Kishimoto, Distribution of shoppers in multi-layered shopping complex : Estimation of shopper density considering escalators, elevators, stairs, 10th Int. Sp. Syntax Symp. (2015) 1-11.

https://keio.pure.elsevier.com/ja/publications/distribution-of-shoppers-in-multilayered-shopping-complex-estima (accessed May 30, 2019).

[37] K. Al-Sayed, Space Syntax methodology. A teaching guide for the MRes/MSc Space Syntax course (version 5), 2014. http://discovery.ucl.ac.uk/1415080/1/AlSayed_SpaceSyntax-manual_2018.pdf (accessed May 30,2019).

[38] C.S. Kim, H. Ko, K.J. An, Development of 3D visibility analysis models using NURBS in a residential development, Int. J. Smart Home. 9 (2015) 151-160. https://doi.org/10.14257/ijsh.2015.9.1.16.

[39] A. Jorgensen, Beyond the view: Future directions in landscape aesthetics research, Landsc. Urban Plan. 100 (2011) 353-355. https://doi.org/10.1016/j.landurbplan.2011.02.023.

[40] C. Lonergan, N. Hedley, Unpacking isovists: A framework for 3D spatial visibility analysis, Cartogr. Geogr. Inf. Sci. 43 (2016) 87-102. https://doi.org/10.1080/15230406.2015.1065761.

[41] M.L. Benedikt, To take hold of space: isovists and isovist fields, 1979. https://doi.org/10.1068/b060047.

[42] C.R. V. Tandy, The isovist method of landscape survey, Symp. Methods Landsc. Anal. (1967) 9-10.

[43] M. Benedikt, To take hold of space: isovists and isovists fields, Environ. Plan. B Plan. Des. 6 (1979) 47-65. https://doi.org/10.1513/AnnalsATS.201407-297PS.

[44] M. Batty, Exploring isovist fields: Space and shape in architectural and urban morphology, Environ. Plan. B Plan. Des. 28 (2001) 123-150. https://doi.org/10.1068/b2725.

[45] S.W. Astek, SULEIMAN W ., JOLIVEAU T .\& FAVIER E ., 2012 - A New Algorithm for 3D Isovist . In 15th International Symposium on Spatial Data Handling Geospatial dynamics, geosimulation and explo ..., (2015).

[46] J.M. Wiener, J.M. Wiener, G. Franz, Isovists as a Means to Predict Spatial Experience and Behavior Trauma Processing in the UK Police View project Spatial Memory and aging View project Isovists as a means to predict spatial experience and behavior, (2004). https://doi.org/10.1007/978-3-540-32255-9_3.

[47] C.D. Lonergan, Advancing Tsunami Risk Communication through Geographic Vizualization, (2011). http://summit.sfu.ca/item/14729 (accessed May 30, 2019).

[48] D. Fisher-Gewirtzman, 3D models as a platform for urban analysis and studies on human perception of space, (2012) 01001. https://doi.org/10.1051/3u3d/201201001.

[49] A. Boddington, J. Boys, Re-Shaping Learning: A Critical Reader: A Critical Reader : the Future of Learning Spaces in a Post-compulsory Education, 2012. https://doi.org/10.1007/978-94-6091-609-0. 
[50] B. Bligh, I. Pearshouse, Doing Learning Space Evaluations, in: Re-Shaping Learn. A Crit. Read., 2011: pp. 3-18. https://doi.org/10.1007/978-94-6091-609-0_1.

[51] K.E. Matthews, V. Andrews, P. Adams, Social learning spaces and student engagement, High. Educ. Res. Dev. 30 (2011) 105-120.

https://doi.org/10.1080/07294360.2010.512629.

[52] D. Holley, C. Dobson, Encouraging student engagement in a blended learning environment: The use of contemporary learning spaces, Learn. Media Technol. 33 (2008) 139-150. https://doi.org/10.1080/17439880802097683.

[53] D. Harrop, A study exploring learners' informal learning space behaviors, attitudes, and preferences, n.d.

[54] X. Wu, S. Law, T. Heath, K. Borsi, Spatial configuration shapes student social and informal learning activities in educational complexes, in: Proc. - 11th Int. Sp. Syntax Symp. SSS 2017, 2017. http://www.11ssslisbon.pt/docs/proceedings/papers/33.pdf (accessed June 27, 2019).

[55] X. Dai, Q. Dong, J. Guo, Production of spatial complexity in an educational building, n.d.

[56] I. Ajzen, From Intentions to Actions: A Theory of Planned Behavior, in: Action Control, Springer Berlin Heidelberg, 1985: pp. 11-39. https://doi.org/10.1007/978-3642-69746-3_2.

[57] J. Teller, A spherical metric for the field-oriented analysis of complex urban open spaces, Environ. Plan. B Plan. Des. 30 (2003) 339-356. https://doi.org/10.1068/b12930.

[58] A. Heumann, 3d Spatial Isovist - Grasshopper, (n.d.). https://www.grasshopper3d.com/video/3d-spatialisovist? $\mathrm{id}=2985220 \% 3 \mathrm{AVideo} \% 3 \mathrm{~A} 150761$ \&page=1\#comments (accessed May 25, 2020).

[59] D. Radcliffe, H. Wilson, D. Powell, B. Tibbetts, Designing next generation places of learning: Collaboration at the pedagogy-space-technology nexus, Univ. Queensl. (2008) 1-20. http://www.uq.edu.au/nextgenerationlearningspace/ (accessed June 5, 2019).

[60] M.B. Brown, J.K. Lippincott, Learning Spaces More than Meets the Eye, Educ. Q. 289 (2003) 14-16. https://doi.org/83.

[61] $\mathrm{X} . \mathrm{Wu}$, The design qualities and spatial organisation for higher education informal learning spaces, (2018). http://eprints.nottingham.ac.uk/52362/ (accessed June 15, 2019).

[62] S. Rauf, K. Tamalanrea, S. Wunas, E. Study, R.A. Barkey, E. Study, S.A. Adisasmita, E.S. Program, Travel Behavior of Students To Campus Based Spatial, 2015. http://eng.unila.ac.id/wp-content/uploads/2015/08/RT160.pdf (accessed June 13, 2019).

[63] S.N. Weerasinghe, D. Dissanayake, Understanding Human Walking Behaviour in relation to Built Environment: A Mobile GIS Approach (With Special Reference to Educational Environments), 2017. http://huckg.is/gisruk2017/GISRUK_2017_paper_46.pdf (accessed June 13, 2019).

[64] C. Newton, Vertical schools on the rise in Australian cities |ArchitectureAU, (n.d.). https://architectureau.com/articles/vertical-schools-on-the-rise/ (accessed May 25, 2020).

[65] C. Groesbeck, Creating a vertical university in an urban environment, CTBUH J. (2013) 20-25. https://scholar.google.co.uk/scholar?hl=en\&as_sdt=0\%2C5\&q=Architecture\%2FDesig 
$\mathrm{n} \% 3 \mathrm{~A}+$ Creating $+\mathrm{a}+$ Vertical+University $+\mathrm{in}+\mathrm{an}+$ Urban+Environment\&btnG $=$ (accessed June 18, 2019).

[66] K. Yeang, Reinventing the skyscraper : a vertical theory of urban design, (2002) 223. https://books.google.co.uk/books?id=KoRPAAAAMAAJ\&q=ken+yeang+architect+en vironment + open + space $\& d q=$ ken + yeang + architect + environment + open + space $\&$ hl $=$ en $\&$ $\mathrm{sa}=$ X\&ved=0ahUKEwjv062t6rXeAhVIzaQKHa9ADZMQ6AEIQDAF (accessed June 18, 2019).

[67] P. Oldfield, The Sustainable Tall Building, 2019. https://doi.org/10.4324/9781315695686.

[68] A. Wood, Rethinking the Skyscraper in the Ecological Age: Design Principles for a New High-Rise Vernacular, Int. J. High-Rise Build. 4 (2015) 91-101.

https://doi.org/10.21022/IJHRB.2015.4.2.091. 


\section{APPENDIX - INTERVIEW FORM}

\section{Introduction}

\section{Welcome and introduction of interview}

\section{$\underline{\text { Objective }}$}

The objective of these interviews is to obtain an understanding of how the spatial openness of the Telford Exhibition Hall impacts student activities.

\section{Process}

I will be audio recording our conversations during the interview so I can revisit and reflect on the information provided. We respect your right to privacy. Our Ethical Clearance ensures that any information that is obtained in connection with this study and that could be identified as relating to you will remain confidential. If you decide to participate in the interview, you are free to discontinue participation at any time without prejudice.

\section{$\underline{\text { 2. Questions }}$}

\section{Personal Background Information}

1. Could you please introduce yourself?
a) Which department are you in?
b) What subject are you studying?
c) Which year are you in?
d) Where is your nearest classroom or workplace?

\section{Frequency, Activity and Reasons}

2. What brings you to use this atrium?

3. Which types of activities do you normally do there?

4. Which ceiling height do you select for doing those activities? Why?

\section{Student perceptions on spatial openness of the atrium}

5. Who do you think this space was designed for?

6. How do you think this space should be used?

7. Compared with a one-storey-height space in a social educational space, what does the three-storey-height space atrium provide you with?

\section{Student voice:}

8. What is your favourite Telford Exhibition Hall story/memory? 